\title{
Impacto medioambiental de la minería y la metalurgia del cobre durante la Edad del Bronce en Kargaly (región de Orenburgo, Rusia)
}

\author{
Environmental impact of copper mining and metallurgy during the Bronze Age at Kargaly \\ (Orenburg region, Russia)
}

Juan Manuel Vicent García (*)

M. ${ }^{a}$ Isabel Martínez Navarrete $(*)$

José Antonio López Sáez (**)

Ignacio de Zavala Morencos (***)

\section{RESUMEN}

Kargaly (región de Orenburgo, Rusia) es una región cuprífera explotada entre los milenios IV y II cal BC y los siglos XVIII y XX d.C. El objetivo del artículo es estudiar comparativamente el impacto de estos episodios mineros en la distribución de los recursos forestales de la región, para aproximar la escala de las operaciones minero-metalúrgicas prehistóricas. Para ello se analizan con métodos estadísticos inferenciales y multivariantes dos secuencias paleopalinológicas procedentes de depósitos naturales de la región y se comparan con un muestreo regional de la lluvia polínica reciente apoyado por un modelo analítico del paisaje actual y con los datos antracológicos procedentes del asentamiento del Bronce Final Gorny 1. Los análisis confirman la gran escala del impacto de la minería prehistórica en la cubierta forestal desde sus inicios, pero también los efectos de las prácticas pastoriles en las fases posteriores al final de la misma. Estos resultados permiten descartar el cambio climático como principal explicación de la variabilidad diacrónica en el registro palinológico, y confirman la viabilidad del enfoque propuesto como medio de inte-

(*) Grupo Prehistoria social y económica, Instituto de Historia, Centro de Ciencias Humanas y Sociales, CSIC. C/ Albasanz 26-28. 28037 Madrid. Correos electrónicos: juan.vicent@cchs.csic.es, isabel.martinez@cchs.csic.es

(**) Grupo Arqueobiología, Instituto de Historia, Centro de Ciencias Humanas y Sociales, CSIC. C/ Albasanz 26-28. 28037 Madrid. Correo electrónico: joseantonio.lopez@cchs.csic.es

(***) Dpto. de Ingeniería Cartográfica, Geodesia y Fotogrametría. Escuela Universitaria de Ingeniería Técnica Agrícola. Universidad Politécnica. Ciudad Universitaria s/n. $28040 \mathrm{Ma}-$ drid. Correo electrónico: ignacio.zavala.morencos@upm.es

Recibido: 30-IX-2010; aceptado: 18-X-2010. grar las disciplinas paleoambientales en la Arqueología del Paisaje.

\begin{abstract}
Kargaly (Orenburg, Russia) is a copper-producing region in which two main phases of mining activity have taken place: the $4^{\text {th }}-2^{\text {nd }}$ millennia $B C$ and the $18^{\text {th }}-20^{\text {th }}$ centuries AD. This article is a comparative study on the impact of those mining episodes in the distribution of the forest resources in the region, aimed to estimate the scale of prehistoric mining and metallurgical works. For that purpose two paleopalinological sequences obtained from natural deposits located in Kargaly are analysed by inferential Statistics and Multivariate Methods. The results are compared both with a regional sampling of recent pollen rain supported by an analytical model of the present day landscape, and with the anthracological data coming from the Late Bronze Age settlement of Gorny 1. Analysis confirm the large scale of the prehistoric mining impact on the forest cover from the beginnings, as well as the strong effect of husbandry once mining works ended. These results allow us to dismiss a climatic change as main explanation for the detected diachronic variability in the palinological record. They also prove the viability of the proposed approach as a means of integrating the paleoenvironmental disciplines in Landscape Archaeo$\log y$.
\end{abstract}

Palabras clave: Eurasia; Prehistoria reciente; Holoceno; Combustible; Paleoecología; Carbono 14; Arqueología cuantitativa; Arqueología del Paisaje.

Key words: Eurasia; Late Prehistory; Holocene; Fuel; Palaeocology; Radiocarbon; Quantitative Archaeology; Landscape Archaeology. 


\section{INTRODUCCION}

En las últimas décadas la investigación sobre minería y metalurgia prehistóricas, que venía orientándose casi en exclusiva hacia la tecnología, ha considerado de modo creciente los aspectos contextuales, sociales, culturales y medioambientales (Knapp 1998: 8-9; Stöllner 2003). Esta tendencia, al integrar esas actividades en la comprensión de las sociedades prehistóricas, está aportando una dimensión social e histórica a la tecnología. El impacto medioambiental de la minería, la metalurgia y el trabajo del metal, en cambio, ha recibido menor y desigual atención. La polución por elementos pesados (Mighall y Chambers 1993; Grattan et al. 2007; Jouffroy-Bapicot et al. 2007; Breitenlechner et al. 2010) y los datos históricos, etnográficos y botánicos (Healy 1978: 148-152; Horne 1982a,b; Miller 1984; Montero Ruiz 1994: 303-304) se han considerado más que la estimación directa de la biomasa consumida (Agapov et al. 1989; Engel y Frey 1999).

Nuestra contribución se encuadra en los estudios paleoambientales interesados por las bases energéticas de la producción metalúrgica y el impacto de la minería y la metalurgia sobre el medio ambiente. El caso escogido es Kargaly (Vicent et al. 2000; Chernykh et al. 1999; Rovira 1999, 2003, 2004, 2005; Rovira y Happ 2004; Díaz-del-Río et al. 2006; Vicent et al. 2006) (1), un complejo minero metalúrgico excepcional en la estepa euroasiática (Popova 2007: 97) (Fig. 1), investigado por un equipo dirigido por E.N. Chernyj (2), especialista internacional en las primeras culturas metalúrgicas euroasiáticas (Chernykh 1992; Thornton 2009: 28; Renfrew 2009: xvi). La metodología desarrollada en Kargaly se reconoce como uno de los contados programas multidisciplinares emprendidos en Rusia (Korobov 2004), destacándose sus aspectos arqueobiológicos y medioambientales (Kristiansen y Larsson 2005: 173, 384, 421-2; Kristiansen 2007: 153; Kohl 2007: 174; Popova 2007: 97). Otra singularidad es la publicación completa y

(1) La participación española ha sido financiada por los proyectos PS95-0031 (1996-1999), PB98-0653 (1999-2002) y BHA2003-08575 (2003-2006) dirigidos por M.'I. Martínez Navarrete y por las becas de estancias cortas del convenio bilateral CSIC- Academia Rusa de Ciencias.

(2) En las trasliteraciones del ruso al español seguimos a Presa (ed.) 1997. puntual de sus resultados (Chernyj 2002a, b, c, d, 2004, 2005, 2007). Además Kargaly es una de las pocas minas explotadas en las estepas euroasiáticas durante la Prehistoria reciente con una escala sustancial de producción (Chernykh 1994: 62-63; Peterson 2009: 194) a diferencia de la de los afloramientos, dispersos por la región.

Kargaly es un criadero de cobre extendido por unos $1500 \mathrm{~km}^{2}$ (Fig. 1A) del que se extrajeron minerales durante la Edad del Bronce y la primera industrialización rusa. Entre un momento y otro sólo fue frecuentado por pastores nómadas que, en cualquier caso, aparentemente no aprovecharon sus yacimientos. El área de estudio ocupa $500 \mathrm{~km}^{2}$. Allí se documentan once grandes mineralizaciones con evidencias de explotación minera (Fig. 1B) (Chernyj 2002a). Se han localizado tres grandes asentamientos superpuestos a las zonas mineras, correspondientes a la fase prehistórica: Miasnikovski, Ordynski y Gorny 1 de cuyas excavaciones (3-3,5\% de sus aproximadamente 4 ha, Chernyj 2002b: 18) procede la mayoría de la información arqueológica publicada. Además, se localizaron tres probables poblados situados en

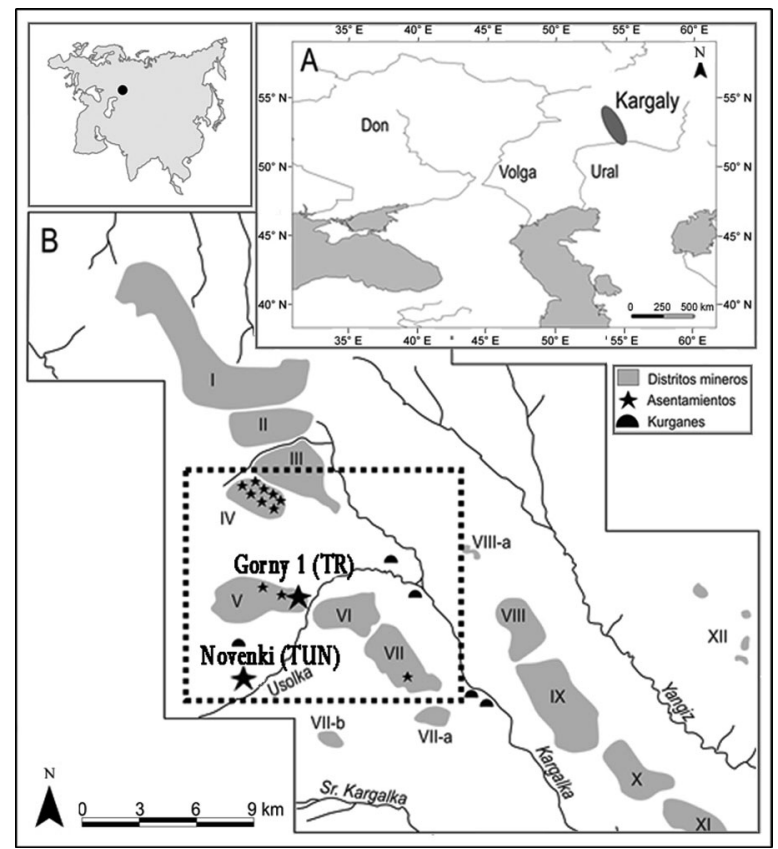

Fig. 1. A: Localización en Eurasia y en la estepa euroasiática del coto minero de cobre de Kargaly (Orenburgo, Rusia). B: Distritos mineros de Kargaly y yacimientos de la Edad del Bronce. El área de estudio está recuadrada (según Chernykh 2002; 90, fig. 2 modificada). 
zonas bajas: Gorny 2 y 3 y Novenki. Finalmente se han excavado cuatro cementerios de kurganes o túmulos funerarios de la Edad del Bronce en las vegas de los ríos Usolka y Kargalka (Chernyj 2005) (Fig. 1B).

Según Chernyj (2002a: 137), la explotación minera de Kargaly se inicia durante la cultura Yamno-Poltavka o Pit grave de la Edad del Bronce Antiguo. Tiene un carácter esporádico y se lleva a cabo mediante zanjas. La máxima intensidad de la explotación prehistórica se produce durante el final de la Edad del Bronce, en el marco de la comunidad Srubnaya clásica o Timber grave (Chernyj 2002d: 125, 2002c: 95).

Los problemas que plantea la interpretación histórica de su registro arqueológico no pueden abordarse desde los datos proporcionados por el registro arqueológico convencional. Esto atañe, en especial, a la escala de la actividad minera y/o metalúrgica al final de la Edad del Bronce, cuando el coto minero habría alcanzado su máximo nivel de actividad. La escala de distribución de los productos metálicos de la minería de Kargaly (Chernyj 2007: 96, Fig. 6.3) parece discrepar del muy limitado desarrollo de la diferenciación social que revela el registro arqueológico local. El alcance de las exportaciones de cobre evoca operaciones mineras a gran escala en el coto. Tales operaciones deberían ir acompañadas de una intensa actividad metalúrgica, que permitiera la circulación a larga distancia de los cobres kargalitanos. Finalmente, esta metalurgia extractiva intensiva sugiere un grado elevado de división del trabajo y especialización técnica. Normalmente ello remite a un grado avanzado de diferenciación y complejidad social, ausente del registro arqueológico local que conocemos (Rolland et al. e.p.).

Los asentamientos excavados en Kargaly no se distinguen sustancialmente de los estándares de la comunidad cultural Srubnaya: escasos indicios de diferenciación social en hábitats y enterramientos. Por su parte, los indicadores de la escala de la producción son ambiguos. En el centro del coto hay, al menos, tres hábitats asociados con explotaciones mineras: Gorny, Ordynski, Miasnikovski. La excavación en la de Gorny ha revelado obras mineras de importantes dimensiones y talleres metalúrgicos. Sin embargo es imposible cartografiar con precisión y coordenar en el tiempo la extensión total de las operaciones mineras en el conjunto del coto ni su grado de inten- sidad. Esta evidencia directa sólo indica las condiciones locales, sin que sea posible hacer generalizaciones en relación con los problemas reseñados al principio.

El Proyecto Kargaly su propuso abordar estos problemas desde la Arqueología del Paisaje, explorando las relaciones entre recursos forestales y escala de la actividad minero-metalúrgica en los dos sentidos mencionados: como indicadores del impacto de las actividades productivas en el paisaje y de la capacidad de producción metalúrgica local, atendiendo al nexo entre disponibilidad de energía y rendimiento energético del proceso metalúrgico. Los experimentos metalúrgicos de $\mathrm{S}$. Rovira (1999; Horne 1982a) facilitan los parámetros para modelizar el rendimiento energético del proceso metalúrgico local.

En las condiciones de relativa escasez de recursos forestales de la estepa arbolada (formación a la que corresponde el paisaje de Kargaly), los bosques y sus variaciones a lo largo del tiempo pueden ser utilizados como proxy de las variaciones correlativas en la escala de la actividad minero-metalúrgica local (Vicent et al. 2000; Vicent et al. 2006). Un escenario de cambios significativos en la distribución de las masas forestales entre las fases previas al Bronce Final y la de su máxima expansión o fase Srubnaya podría atribuirse, bajo ciertas condiciones, a un alto impacto antrópico en el entorno. Ese escenario sería un indicador fiable de una escala intensiva de la producción minero-metalúrgica. A la inversa, la ausencia de tales cambios confirmaría la baja intensidad de dicha actividad, remitiendo a un consumo sostenible de recursos energéticos, cuyos umbrales pueden ser modelizados.

El objetivo del presente trabajo es utilizar los datos paleoambientales producidos por la exploración arqueológica del complejo de Kargaly como base empírica para una aproximación de este tipo a la historia forestal de la región.

Existen dos series de datos que proporcionan información sobre la evolución de la cubierta forestal de Kargaly: palinológicos y antracológicos. La palinología arqueológica permite una aproximación a la descripción de las cubiertas vegetales y su evolución en el tiempo. El supuesto metodológico es que la proporción de polen de un taxón en una muestra de lluvia polínica es una función de la superficie efectiva ocupada por dicho taxón en un radio en torno al punto de obtención, definido por la movilidad del polen, la productividad 
polínica del taxón y otros factores (Hicks y Birks 1996; Broström et al. 1998; Broström et al. 2005; Bennett y Hicks 2005). Diseñar un modelo de esta relación funcional entre la distribución efectiva de la vegetación y su representación en los espectros polínicos es el objetivo de enfoques, desarrollados durante las últimas décadas. Destaca el del Best Modern Analogue (BMA) que utiliza la vegetación actual y su representación palinológica como base para crear modelos de la vegetación en el pasado (Overpeck et al. 1985; Guiot 1990; Tarasov et al. 2007).

Salvando las limitaciones que se indicarán, asumimos que el número de palinomorfos pertenecientes a especies recogidas en un espectro polínico obtenido en un punto concreto representa, en alguna medida, la distribución de la vegetación en el entorno espacial y temporal de dicho punto. Por lo tanto, la comparación de la composición cualitativa y cuantitativa de distintos espectros distribuidos en el tiempo y en el espacio deben permitir una descripción de la distribución general de la vegetación y sus cambios en el tiempo. Como esta representación está mediatizada por factores dependientes de la propia naturaleza del polen y de variables contextuales, tafonómicas, topográficas, etc., la evidencia polínica no puede traducirse directamente a términos biogeográficos. La productividad del polen varía según la especie y su dispersión depende también de las condiciones ambientales locales. Estos factores distorsionan la variación que depende de factores biogeográficos (número y cercanía de plantas emisoras al punto de muestreo). Pero, en la medida en que la mayoría de dichos factores pueden controlarse, comparar las distribuciones de polen debería permitir identificar cambios de tendencia significativos en la biogeografía de los recursos forestales.

Por último, la interpretación del cambio diacrónico plantea además otras cuestiones. Los paleoambientalistas suelen atribuir a cambios climáticos las modificaciones a largo plazo en la distribución de la vegetación. Esta explicación puede considerarse la "hipótesis nula" de cualquier argumentación sobre el particular. En este esquema argumental, la "hipótesis alternativa" (es decir, la que queda verificada al descartar la "hipótesis nula") sería otra de carácter histórico: los cambios en la distribución de la vegetación dependen de la acción social sobre el entorno. En los procesos reales ambos planos causales están entrelazados de forma compleja. Los procesos de cambio climático globales se manifiestan de formas específicas en los contextos locales, y transcurren normalmente en ciclos de larga duración. Por su parte los impactos sociales sobre el medio pueden manifestarse a distintas escalas (local, regional, etc.) y planos temporales dependiendo de su carácter coyuntural (sucesos concretos, como un episodio de explotación minera) o estructural (cambios en la tecnología y/o el modo de producción).

En este trabajo adoptaremos la "hipótesis alternativa" de que los cambios observables en el registro paleoambiental de Kargaly se explican únicamente por el impacto social sobre el medio en un sentido puramente heurístico, que deberá ser contrastado en el futuro mediante al análisis de todos los datos disponibles, y no sólo, como haremos aquí, de los relativos a las especies arbóreas. En cualquier caso no hay evidencias regionales sobre episodios de cambio climático entre el IV milenio cal. B.C. y la actualidad que puedan invalidar nuestras hipótesis interpretativas a escala local.

El enfoque que se propone se basa en el análisis comparativo, apoyado por el uso de métodos cuantitativos, de la amplia serie de espectros polínicos recientes y fósiles recuperados en un área representativa del conjunto del territorio de Kargaly con objeto de determinar si hubo cambios significativos en la distribución de los recursos forestales entre el período de la minería prehistórica (IV-II milenio cal. B.C.) y la actualidad. Los datos antracológicos procedentes de la excavación del asentamiento de la Edad del Bronce Gorny 1, se utilizarán como referencia comparativa para la interpretación de los resultados de este análisis.

En este contexto, las hipótesis centrales de la investigación son: (1) el desarrollo de la ocupación del territorio de Kargaly durante el Edad del Bronce y las actividades minero-metalúrgicas con ella asociadas modificaron la distribución de las especies arbóreas locales. Ello puede observarse comparando los espectros polínicos fósiles anteriores y posteriores a dicha ocupación. (2) Estos cambios pueden ser interpretados en términos biogeográficos mediante la comparación controlada de los espectros polínicos fósiles y una muestra de la lluvia polínica reciente asesorada por un modelo analítico del paisaje, de acuerdo con la filosofía del enfoque $B M A$. 


\section{MATERIALES Y MÉTODOS}

En el marco del proyecto Kargaly se recuperaron 166 espectros polínicos, procedentes de sondeos en 2 depósitos naturales y 3 depósitos arqueológicos (López-Sáez et al. 2002: 160; López et al. 2003: 77). Además se obtuvieron 76 muestras en el nivel superficial del suelo distribuidas en tres series, que representan la lluvia polínica reciente (Vicent et al. 2000).

El tratamiento y preparación de las muestras fue el mismo para todas las series. Para este trabajo se han seleccionado dos series paleopalinológicas de los depósitos naturales y la totalidad de las muestras de la lluvia polínica. Se excluyen las series procedentes de depósitos arqueológicos para minimizar en lo posible los sesgos antrópicos.

Las series paleopalinológicas fueron fechadas mediante dataciones de C14 sobre paleosuelo y concentraciones de polen. Ofrecen sendas secuencias continuas desde el IV milenio cal B.C. hasta la actualidad (véanse secciones 3.2 y 3.3 de este artículo).

Las muestras de la lluvia polínica serán la referencia comparativa para la interpretación biogeográfica del registro paleopalinológico. Para ello sus emplazamientos fueron seleccionados siguiendo un modelo de muestreo orientado a obtener una caracterización palinológica del área de trabajo. Los criterios de muestreo se describen en la sección 3.4.

En la sección 3.5 estas tres series de datos se discuten según criterios arqueológicos para establecer una periodización que paralelice su contenido paleoambiental con las etapas históricas del complejo de Kargaly. Esta periodización será el criterio básico de organización de la información palinológica. Nuestros intereses son muy concretos y relativos a las plantas leñosas susceptibles de ser usadas como combustible. Por esta razón se han seleccionado sólo los morfotipos palinológicos correspondientes a dichas especies (inventario en la sección 3.1). Ello limitará igualmente los objetivos del trabajo concernientes a la caracterización general del clima y la vegetación.

Paralelamente a la investigación palinológica se hizo otra sobre el paisaje actual de Kargaly, destinada a elaborar un modelo analítico del mismo que apoyara la interpretación biogeográfica de la variabilidad palinológica. Con este fin se realizó un programa de teledetección espacial, así como inventarios florísticos y descripciones normalizadas del territorio. Esta parte de la investigación y sus resultados en cuanto a la caracterización de la distribución actual de los recursos forestales, se describen en la sección 4.

El conjunto de datos será objeto de un análisis comparativo, según las hipótesis de trabajo. La asunción metodológica básica es que los espectros polínicos son distribuciones de probabilidad. Es decir, la frecuencia de los distintos palinomorfos representados en él son estimaciones de la probabilidad de que un grano de polen escogido al azar en un punto del territorio pertenezca a una especie productora determinada. Desde este punto de vista los problemas planteados por el análisis comparativo de muestras de polen se abordan como problemas de análisis estadístico. Esta perspectiva puede dar lugar a diferentes marcos analíticos. El que se ha adoptado consiste en asimilar los diferentes morfotipos polínicos identificados en las muestras (taxones) con variables aleatorias independientes, cuyos valores en las distintas muestras pueden ser comparados asumiendo las determinaciones del modelo lineal general. Cada una de las hipótesis de trabajo se aborda desde una estrategia de análisis consistente con este supuesto. La comparación diacrónica se llevará a cabo como un problema de estadística inferencial, tratando de establecer si hay o no diferencias estadísticamente significativas entre las proporciones de polen de los distintos taxones en las fases de la secuencia (sección 5.1). El análisis de la representación palinológica de la distribución actual de los recursos forestales explorará las correlaciones lineales entre taxones (sección 5.4). Finalmente este análisis exploratorio se generalizará, en la forma de un Análisis de Componentes Principales incluyendo las muestras paleopalinológicas, para aproximar una interpretación biogeográfica positiva de la variabilidad diacrónica observada (sección 5.4).

Por último, para contrastar la representación palinológica de los recursos forestales con datos arqueológicos sustantivos sobre sus pautas de uso efectivas, hasta donde nos son conocidas, los resultados del análisis se confrontarán con los datos antracológicos procedentes de la excavación del poblado de la Edad del Bronce Gorny 1 (sección 5.5). 


\section{EL REGISTRO PALINOLÓGICO DE KARGALY}

\subsection{Los datos palinológicos}

La tabla de datos consta de las secuencias trinchera minera de Gorny y turbera de Novenki (en adelante TR y TUN) obtenidas en depósitos naturales (22 y 17 muestras) y las 76 muestras de la lluvia polínica reciente como grupo de control.

Los datos palinológicos se organizaron en "grupos ecológicos" basados en el análisis espacial del inventario florístico. El grupo "árboles y arbustos de la ripisilva local" (en adelante grupo A) contiene las especies actuales de la cubierta forestal. Nos servirá como referencia para el análisis.

Muchos palinomorfos sólo pueden ser identificados a nivel de familia o género. La tabla 1 compara las identificaciones palinológica y botánica de las especies del inventario. La interpretación se resiente por esta limitación metodológica. Por ejemplo, en Kargaly, el género Populus cuenta con dos especies: P. tremula, distribuida por los cursos estacionales de agua, y $P$. nigra, asociada a la ripisilva fluvial. A su vez, el palinomorfo Acer puede corresponder a la especie $A$. platanoides, especie autóctona, pero también a $A$. negundo, cuya introducción se asocia con la colonización rusa de la región durante el siglo XVIII d.C. Otros problemas derivan de la agrupación taxonómica de múltiples especies. Así el morfotipo Prunus recoge una cierta variedad de rosáceas leñosas y Rosaceae las de tipo herbáceo. Comparten un patrón de distribución bastante coherente: zonas áridas, preferentemente colonizando las áreas mineras abandonadas. Sin embargo, alguna especie incluida, como Sorbus aucuparia, tiene preferencia por los bosques galería. No obstante, en general, la mayor parte de las especies agrupadas bajo un mismo identificador palinológico mantienen patrones coherentes de distribución. Ello sucede con Salix, Ulmus o Alnus (6, 3 y 2 especies respectivamente), todas ellas asociadas a la ripisilva fluvial aunque algunas especies (p. ej, de Salix), pueden encontrarse también en los barrancos de deshielo.

Los inventarios florísticos detallados de cada "unidad de muestreo" (el área de $250 \mathrm{~m}$ de radio en torno al punto de extracción de cada muestra) permiten detectar las anomalías producidas por la simplificación taxonómica. Pero no pueden evitar una cierta incertidumbre en el tratamiento esta-

\begin{tabular}{|c|c|}
\hline Morfotipo polínico & Posibles especies correspondientes \\
\hline Acer & Acer platanoides \\
\hline Alnus & Alnus glutinosa \\
\hline & Alnus incana \\
\hline Betula & Betula pendula \\
\hline Fraxinus & Fraxinus excelsior \\
\hline Lonicera & Lonicera xylosteum \\
\hline & Lonicera tatarica \\
\hline Populus & Populus nigra \\
\hline & Populus tremula \\
\hline Prunus $\mathrm{t}$ & Amygdalus nana \\
\hline & Cotoneaster melanocarpa \\
\hline & Crataegus sanguinea \\
\hline & Malus sylvestris \\
\hline & Padus avium \\
\hline & Padus racemosa \\
\hline & Rosa cinnamomea \\
\hline & Rosa majalis \\
\hline & Rubus chamaemorus \\
\hline & Rubus idaeus \\
\hline & Rubus saxatilis \\
\hline & Spiraea crenata \\
\hline & Spiraea capillata \\
\hline Quercus robur $\mathrm{t}$ & Quercus robur \\
\hline Rhammus t & Rhamnus cathartica \\
\hline Ribes rubrum $\mathrm{t}$ & Ribes nigrum \\
\hline Salix & Salix acutifolia \\
\hline & Salix alba \\
\hline & Salix caprea \\
\hline & Salix pentandra \\
\hline & Salix viminalis \\
\hline Sambucus nigra $\mathrm{t}$ & Sambucus nigra \\
\hline Tilia & Tilia cordata \\
\hline Ulmus & Ulmus laevis \\
\hline & Ulmus glabra \\
\hline Viburnum & Viburnum opulus \\
\hline
\end{tabular}

Tab. 1. Correspondencia entre las identificaciones palinológica y botánica de las especies del inventario realizado en el área de trabajo de Kargaly (región de Orenburgo, Rusia) combinadas con la bibliografía (Riabinina 1998). Se han excluido las Rosaceae por la gran variedad de especies con las que están representadas y su enorme amplitud ecológica en la misma.

dístico que, en lo que podamos, señalaremos y valoraremos en el análisis.

Por último, respecto al inventario de taxones, advertimos que, en los análisis detallados, se ha prescindido de Lonicera, Ribes y Viburnum por su escaso valor como recurso energético. Sí se han incluido en la variable agregada "Total de Arbóreas", por su valor como indicador.

Los datos palinológicos primarios consisten en recuentos de las frecuencias con las que cada 
taxón se identifica en una muestra. Su comparación directa carece de significado, prima facie, al estar mediatizada por los factores aludidos y el tamaño de la muestra. Cada estrategia de análisis requerirá una elaboración específica de los datos. En el análisis diacrónico usaremos la concentración polínica expresada en granos de polen por unidad de masa de sedimento. Se calcula añadiendo un número controlado de esporas de Lycopodium durante la preparación de las muestras (Stockmarr 1971).

En la comparación de muestras paleopalinológicas y de control se usarán directamente las frecuencias relativas de los taxones, calculando sus porcentajes sobre la suma base total de palinomorfos identificados en la muestra. De esta suma base se excluyen, como es habitual, los hidro-higrófitos y los microfósiles no polínicos, pero también los palinomorfos del grupo "arbóreas alóctonas" (B). Se busca analizar la variación de las especies arbóreas locales en relación con su propio entorno comparando sus proporciones. La inclusión de pólenes exóticos, a veces muy frecuentes, distorsionaría mucho el modelo. Por ejemplo, en las muestras de Kargaly el polen del grupo B, compuesto en más de un $90 \%$ por el morfotipo Pinus sylvestris, representa un promedio del $20,14 \%$ de la suma base, alcanzando en alguna muestra el 86,02\%. Actualmente no hay coníferas en Kargaly. Su fuerte presencia y rango de variación en las muestras se explica por la ubicuidad del polen de Pinus (Moore et al. 1991) y por los pinares localizados en un radio no menor de $200 \mathrm{~km}$ en torno al coto (Riabinina 1998: 4-6; Chibiliov 1999). El más importante, Buzuluk, ocupa casi 60000 ha (Riabinina 1998: 4; Kremenetski et al. 1999) y está situado a $202 \mathrm{~km}$ al oeste de Kargaly. La difusión anemófila del polen de Pinus explica su amplio rango de variación en las muestras de la lluvia polínica reciente, determinada por la exposición al viento del punto de muestreo. Ello no excluye variaciones diacrónicas, quizá significativas en términos de la secuencia climática regional, que deben discutirse aparte del problema que nos ocupa, y en relación con estudios en curso de los factores geográficos.

\subsection{Turbera de Novenki (TUN)}

La secuencia TUN se obtuvo en un depósito higroturboso localizado en el centro de la cuenca de recepción del río Usolka. A unos $100 \mathrm{~m}$ al norte se había identificado en superficie el contorno de una vivienda semiexcavada. Un sondeo arqueológico de $3 \times 4 \mathrm{~m}$ abierto en su borde descubrió un muro de piedra de hasta $2,5 \mathrm{~m}$ de ancho que protegía la fosa de fundación. El nivel freático impidió profundizar más de $0,35 \mathrm{~m}$. Los materiales recuperados, atribuidos a la cultura Srubnaya (Edad del Bronce Final), no desentonan con la morfología de la vivienda si bien el uso de piedra como material de construcción es infrecuente (Chernyj et al. 2002: 71-74). Es claro que TUN queda dentro del área de influencia del poblado pero ninguna evidencia sugiere que se viera afectado directamente por él. Podemos suponer, por tanto, que su formación no fue de origen antrópico. Tampoco la cuenca de recepción del Usolka registra actividad minera ni en la Prehistoria ni en época reciente.

La columna de sedimentos en TUN se tomó mediante una sonda rusa. Se llegó hasta una profundidad de $80 \mathrm{~cm}$, muestreando cada $5 \mathrm{~cm}$. Sólo se pudo fechar esta muestra a $80 \mathrm{~cm}$ (AA10007 $4270 \mathrm{BP} \pm 103$ ) (López et al. 2003). Un primer análisis de la secuencia polínica refiere su formación a una tasa constante de deposición en un medio acuático, salvo un episodio anómalo que afecta a las muestras centrales. Los valores de la concentración polínica de cada muestra (Fig. 2A) son bastante estables a lo largo de la secuencia, variando dentro de un mismo orden de magnitud, lo que permite interpretar que también eran estables las condiciones de formación del depósito que determinan la concentración polínica (forma de aporte del polen, mecanismo de deposición y naturaleza del sedimento). Sin embargo los valores de concentración de las muestras TUN_45, TUN_50 y TUN_55 son de un orden de magnitud entre tres y diez veces superior al resto. Este hecho sugiere que uno o varios de los determinantes citados sufrieron una alteración significativa de la que resultó una mayor aportación de polen al sedimento. Es muy significativo el hecho de que las esporas de Glomus, un indicador de procesos erosivos (López Sáez et al. 1998; López Sáez et al. 2000), aumenten su peso relativo a partir de la muestra TUN_50 (Fig. 2B). Esta asociación sugiere que la perturbación que afecta a las muestras centrales de la secuencia se relaciona con un episodio erosivo. Posiblemente, en su fase inicial, favorece el arrastre de sedimentos ricos en polen, sustituyendo temporalmente el mecanismo aéreo/ 


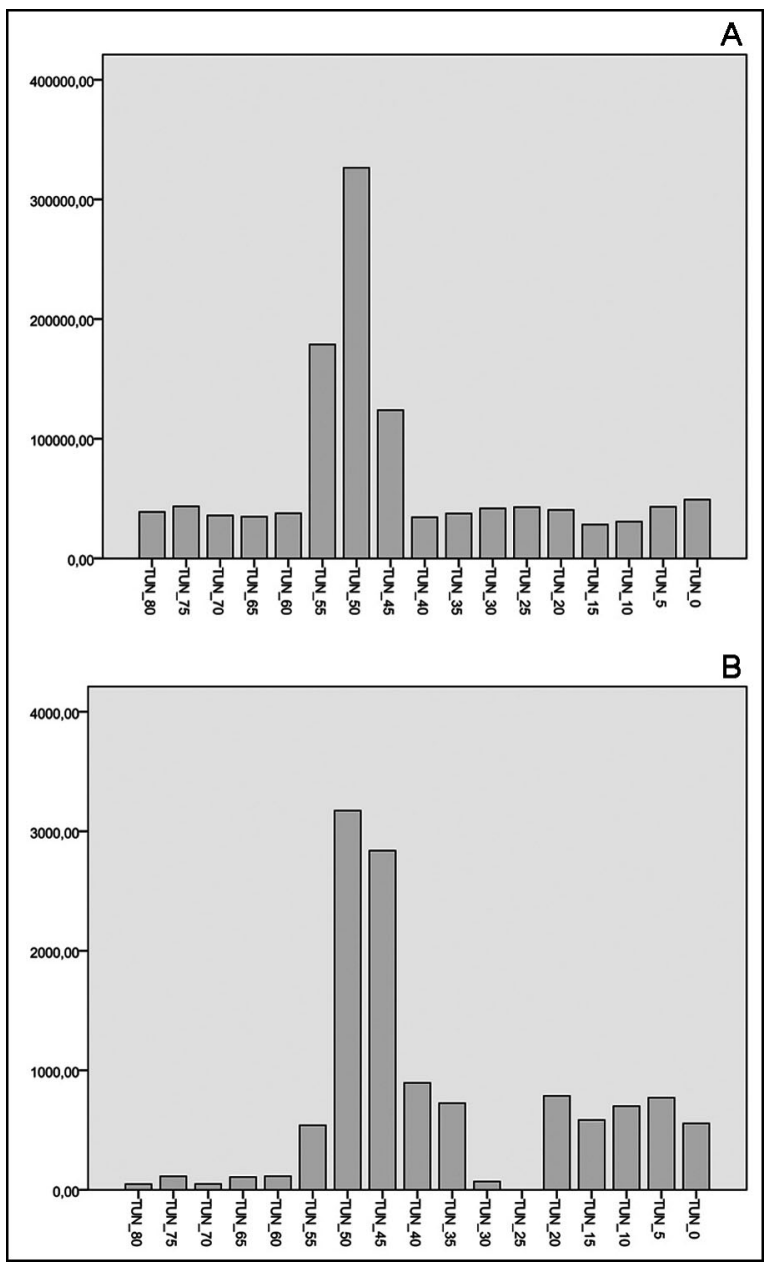

Fig. 2. Turbera de Novenki (TUN) (Kargaly, región de Orenburgo, Rusia). En cada muestra de la secuencia, A: valores de la concentración polínica. B: valores de concentración de las esporas de Glomus.

acuático de aporte de polen, típico del conjunto del depósito. Como la distribución de Glomus es similar en el resto de la secuencia (salvo las muestras TUN_30 y TUN_25), deducimos que las condiciones de formación de la última fase del depósito fueron diferentes a las de la primera y aportaron sedimentos de arrastre.

Faltan datos directos para fechar este episodio erosivo y para valorar su alcance local o regional. Pero, correlacionando la posición relativa de las muestras afectadas (la parte central de la secuencia), la regularidad asumida para la formación del depósito y la fecha absoluta obtenida en su base (TUN_80) es razonable datar el episodio a mediados del II milenio cal BC. Tomando 3000 cal $\mathrm{BC}$ como punto central del intervalo de $2 \sigma$ de la fecha y dividiéndolo por las 17 muestras de TUN la tasa sería de 291 años cal $/ 5 \mathrm{~cm}$. El razonamiento sólo tiene un valor indicativo. Nunca hay una correlación perfecta entre tiempo y profundidad, máxime cuando, como en este caso, el espesor del sedimento correspondiente al episodio erosivo superaría el de los formados en el régimen normal de sedimentación de la turbera. Siendo regular la distancia entre muestras, es muy posible que las tres en cuestión, extraídas en un segmento de unos $15 \mathrm{~cm}$ de la columna, representen un período muy corto de tiempo. De ser así, quizás las extremas, TUN 45 y TUN 55, incluyan sedimentos procedentes del episodio erosivo y otros, previos o posteriores, propios del régimen normal de sedimentación de la turbera. Esto explicaría la gradación observable en los gráficos de concentración.

No obstante, la fecha de mediados del II milenio cal BC para las muestras afectadas resulta plausible, entre otras cosas, porque coincide con la época de ocupación del poblado de Novenki.

En ausencia de indicadores de perturbaciones climáticas regionales, la causa más plausible de la perturbación observada en TUN es la intensa antropización del entorno del poblado. La consiguiente pérdida de la vegetación local habría afectado al depósito del modo descrito. La turbera, por su posición central en la cuenca, sería receptora neta de los sedimentos movilizados por la erosión antrópica. El aumento del área de captación de polen explicaría la gran concentración observada.

\subsection{Trinchera minera de Gorny (TR)}

La segunda secuencia procede de una trinchera de prospección minera a unos $5,5 \mathrm{~km}$ lineales al norte de TUN (Chernyj 2002c). Se sitúa, próxima al borde septentrional de la colina Gorny 1, a $12 \mathrm{~m}$ de donde se asienta un poblado de la Edad del Bronce. Se reconocía en superficie como una depresión oval (43-46 m por 18-21 m) cubierta por vegetación más densa que la del entorno. Se excavaron dos sondeos transversales. En el primero, abierto en 1997 en el borde occidental, una construcción rusa del siglo XVIII había destruido los 0,90-1,10 $\mathrm{m}$ superiores del depósito que se excavó hasta los $3 \mathrm{~m}$. La segunda cata se abrió en 1998 a $18 \mathrm{~m}$ al este de la primera. De cada sondeo se extrajeron sendas secuencias palinológicas. 


\begin{tabular}{|c|c|c|c|c|c|c|c|c|}
\hline \multirow[t]{2}{*}{ MUESTRA } & \multirow{2}{*}{$\begin{array}{c}\text { Cota } \\
\text { m.s.n.m. }\end{array}$} & \multirow[t]{2}{*}{ ID_C14 } & \multirow{2}{*}{$\begin{array}{c}\text { C14 años } \\
\text { BP }\end{array}$} & \multirow{2}{*}{$\begin{array}{c}\text { C14 años } \\
\text { BP }\end{array}$} & \multirow[t]{2}{*}{ D.s. } & \multicolumn{2}{|c|}{$\begin{array}{l}\text { Límites a } 2 \sigma \text { intervalo (cal } \\
\text { BC/AD) }\end{array}$} & \multirow[t]{2}{*}{ Material } \\
\hline & & & & & & inferior & superior & \\
\hline TR_1 & 203,20 & *AA50193 & 3725 & 3725 & 65 & -2340 & -1930 & paleosuelo \\
\hline TR_3 & 203,40 & AA58663 & 7907 & 7907 & 82 & -7050 & -6600 & polen c. \\
\hline TR_5 & 203,60 & AA58664 & 9110 & 9110 & 140 & -8750 & -7800 & polen c. \\
\hline TR_7 & 203,80 & AA58665 & 4380 & 4380 & 61 & -3330 & -2890 & polen c. \\
\hline TR_9 & 204,00 & AA58666 & 3734 & 3734 & 54 & -2300 & -1960 & polen c. \\
\hline TR_- $11 \mathrm{a}$ & 204,20 & AA58668 & 3417 & 3417 & 38 & -1880 & -1610 & polen c. \\
\hline TR_11b & 204,20 & AA58667 & 3391 & 3391 & 38 & -1870 & -1530 & polen c. \\
\hline TR_13a & 204,40 & AA58670 & 3264 & 3264 & 38 & -1630 & -1440 & polen c. \\
\hline TR_13b & 204,40 & AA58669 & 2980 & 2980 & 38 & -1380 & -1050 & polen c. \\
\hline TR_15 & 204,60 & *AA50194 & 3120 & 3120 & 150 & -1750 & -900 & paleosuelo \\
\hline TR_17 & 204,80 & AA58674 & 2756 & 2756 & 37 & -1000 & -820 & polen c. \\
\hline TR_19a & 205,00 & AA58671 & 2221,00 & 2221,00 & 52 & -400 & -160 & polen $\mathrm{c}$. \\
\hline TR_19b & 205,00 & AA58672 & 1999,00 & 1999,00 & 36 & -100 & 80 & polen c. \\
\hline TR_21a & 205,20 & AA58675 & 1547,00 & 1547,00 & 73 & 350 & 650 & polen c. \\
\hline TR_21b & 205,20 & AA58676 & 1174,00 & 1174,00 & 47 & 710 & 990 & polen c. \\
\hline TR_23 & 205,40 & AA58677 & 1366,00 & 1366,00 & 37 & 600 & 770 & polen $\mathrm{c}$. \\
\hline CR_11 & 206,25 & *CSIC 1257 & 2474 & 2474 & 61 & -770 & -410 & paleosuelo \\
\hline CR_0_1 & 205,10 & *CSIC1258 & 3889 & 3889 & 38 & -2480 & -2230 & paleosuelo \\
\hline TUN_80 & 210,20 & A10007 & 4270 & 4270 & 103 & -3350 & -2550 & paleosuelo \\
\hline
\end{tabular}

Tab. 2. Dataciones $\mathrm{C} 14$ convencional (CSIC, *AA) y $A M S(A A)$ de las secuencias paleopalinológicas en depósitos naturales estudiadas en el coto minero-metalúrgico de Kargaly (región de Orenburgo, Rusia). Secciones central (TR) y occidental (Casa Rusa, CR) de la trinchera minera del poblado Gorny 1 y turbera de Novenki (TUN) (véase Fig. 3). AA \# NSF-Arizona AMS Laboratory; *AA \# Radiocarbon Laboratory Tucson Arizona; CSIC \# Instituto Química-Física Rocasolano, CSIC, Madrid. D.s.: Desviación estándar; Polen c.: polen concentrado y palinodebris.

El sondeo "Casa Rusa" consta de 19 muestras obtenidas cada 5 ó $10 \mathrm{~cm}$ desde la base de la construcción hasta los 2,5 m de profundidad. Los sedimentos de las muestras inferior (CSIC-1258) y a $15 \mathrm{~cm}$ de la superficie (inicio chernozem) (CSIC-1257) se emplearon en su totalidad para la datación (Chernyj 2002c: 136). El tratamiento de la secuencia no incluyó la concentración de polen (López-Sáez et al. 2002: 160). Dada su importancia en nuestra argumentación, no usaremos los datos publicados.

La cata TR, ya mencionada, conservaba íntegro el depósito de techo a base (Chernyj 2002b). En su perfil occidental se tomaron 26 muestras cada 5 ó $10 \mathrm{~cm}$, desde la superficie hasta los 2,50 $\mathrm{m}$, donde terminaba la colmatación con contenido orgánico de la trinchera. A partir de concentraciones de polen extraídas de 12 de ellas (3) se obtuvieron 16 fechas AMS (4 dobles) (Chernyj y

(3) La muestra a 203,30 cm de la superficie no contenía materia orgánica suficiente para la datación. Otra era estéril.
Martínez Navarrete 2004, 2005) (Tab. 2; Fig. 3). Por debajo se fecharon 5 muestras del sedimento contenido en unas madrigueras practicadas en los derrumbes arcillosos de las paredes y en las paredes mismas. La A-10262 data la apertura de esta sección antes del 4050-3350 cal BC, durante la fase Yamnaya (Edad del Bronce Antiguo) (Chernyj 2002b: 132-137). Pese a la docena de metros que separan TR del área de intensa ocupación Srubnaya apenas se recuperaron una treintena de piezas y sólo en el paquete superior. A su vez, el cotejo de las dataciones obtenidas en TR con las procedentes del poblado demuestra que la estructura estaba abierta y en colmatación gradual, mientras la colina era usada por los mineros y metalúrgicos de las fases posteriores de la Edad del Bronce.

Los excavadores distinguieron cuatro paquetes estratigráficos. Los inferiores muy arcillosos, con escaso contenido orgánico, proceden del desplome y descomposición del material geológico en el que se abrió la estructura. Los superiores, 


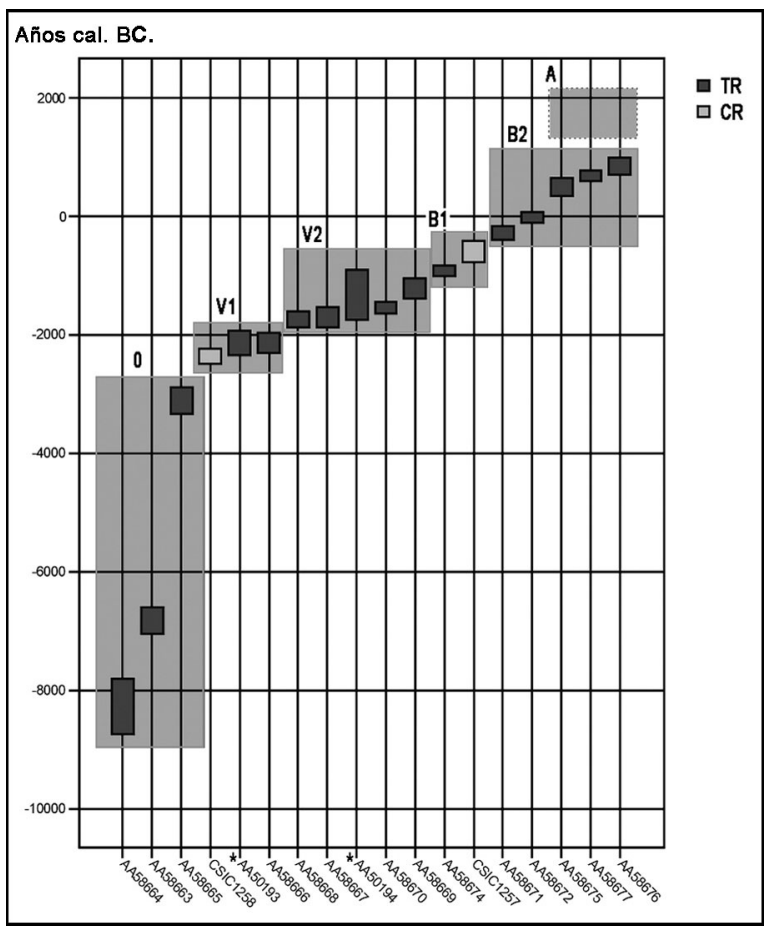

Fig. 3. Secciones central (TR) y occidental (Casa Rusa, $\mathrm{CR})$ de la trinchera minera del poblado Gorny 1 (Kargaly, región de Orenburgo, Rusia). Muestras fechadas por C14 convencional (CSIC, *AA) y $A M S(A A)$. Intervalos de calibración a $2 \sigma$ en orden cronológico creciente. Los grupos estratigráficos aparecen recuadrados. AA \# NSF-Arizona AMS Laboratory; *AA \# Radiocarbon Laboratory Tucson Arizona; CSIC \# Instituto Química-Física Rocasolano, CSIC, Madrid.

básicamente constituidos por chernozem, el suelo vegetal propio de la estepa, se formaron in situ. La TR 15, a 1,30 $\mathrm{m}$ de profundidad, marca la transición entre los dos regímenes de formación del depósito. Su datación (AA50194 $3120 \pm 120$ ) incluye en su intervalo de calibración a $1 \sigma$ (1610-1130 cal BC) las fechas más recientes del poblado. Asumimos que el cambio de régimen sedimentario se conecta con el abandono de la ocupación Srubnaya de la colina. La figura 3 sugiere que, durante el primero, los depósitos se formaron en períodos breves: los intervalos de calibración se agrupan de forma anárquica en un mismo "escalón" temporal. Después el proceso es regular y gradual: los grupos de fechas se suceden a lo largo de una pendiente.

La sucesión de dataciones del primer tramo es aberrante: tres dataciones, claramente previas a la fecha probable de apertura de la trinchera marca- da por las madrigueras, se superponen a una datación coherente con esta última. A su vez, la datación por encima de la última de ellas equivale prácticamente a la citada en último lugar. De todo ello cabe deducir que, entre 2340 y 1930 cal BC (intervalo a $2 \sigma$ de AA50193 TR_2 que incluye el de AA50666 TR_9), la sedimentación natural se vio interrumpida por derrumbes que arrastraron al fondo de la trinchera paquetes del paleosuelo superficial, formados entre 8600 y 2910 cal BC. Consiguientemente descartamos del análisis las muestras T_3 a T_8 presuntamente implicadas en el episodio.

Atendiendo a estas consideraciones, distinguimos en la secuencia TR cuatro segmentos, coherentes con la asignación estratigráfica de los excavadores (Chernyj 2002b) (Fig. 3) (4):

(1) Paquete V1 previo a la ocupación Srubna$y a$. Sus fechas quedan dentro del intervalo 2340-1930 cal BC (calibración a $2 \sigma$ de la datación AA50193). Se excluyen las muestras involucradas en el proceso de inversión descrito, incluyendo las dos muestras de base (bloque 0).

(2) Paquete V2, contemporáneo de la ocupación Srubnaya e inmediatamente posterior a la misma. Sus dataciones indican un período no anterior a 1880 cal BC (límite inferior del intervalo a $2 \sigma$ de la datación AA58668), ni posterior a 900 cal BC (límite superior del intervalo a $2 \sigma$ de AA50194).

(3) Paquetes B1 y B2, período de formación de chernozem. Se inicia después de la última fecha citada. Se desarrolla sin interrupción aparente hasta aproximadamente $1000 \mathrm{cal} \mathrm{AC}$.

(4) Paquete A, período reciente: las tres muestras más superficiales.

Si consideramos las variaciones en la concentración polínica (Fig. 4A) y la proporción de Glomus (Fig. 4B) observamos algunas analogías con el depósito TUN. Tres grupos de muestras tienen valores muy altos de concentración polínica: las muestras excluidas del bloque (0), el conjunto de muestras del bloque (2) y las dos últimas muestras del (4). Siempre los valores altos de concentración coinciden con cantidades apreciables de Glomus. Como en el caso de TUN, es plausible que correspondieran a tres procesos erosivos locales de una cierta intensidad que implicarían la

(4) Se presenta aquí la trasliteración rusa: a, б, B = A, B, V para facilitar la consulta bibliográfica. 


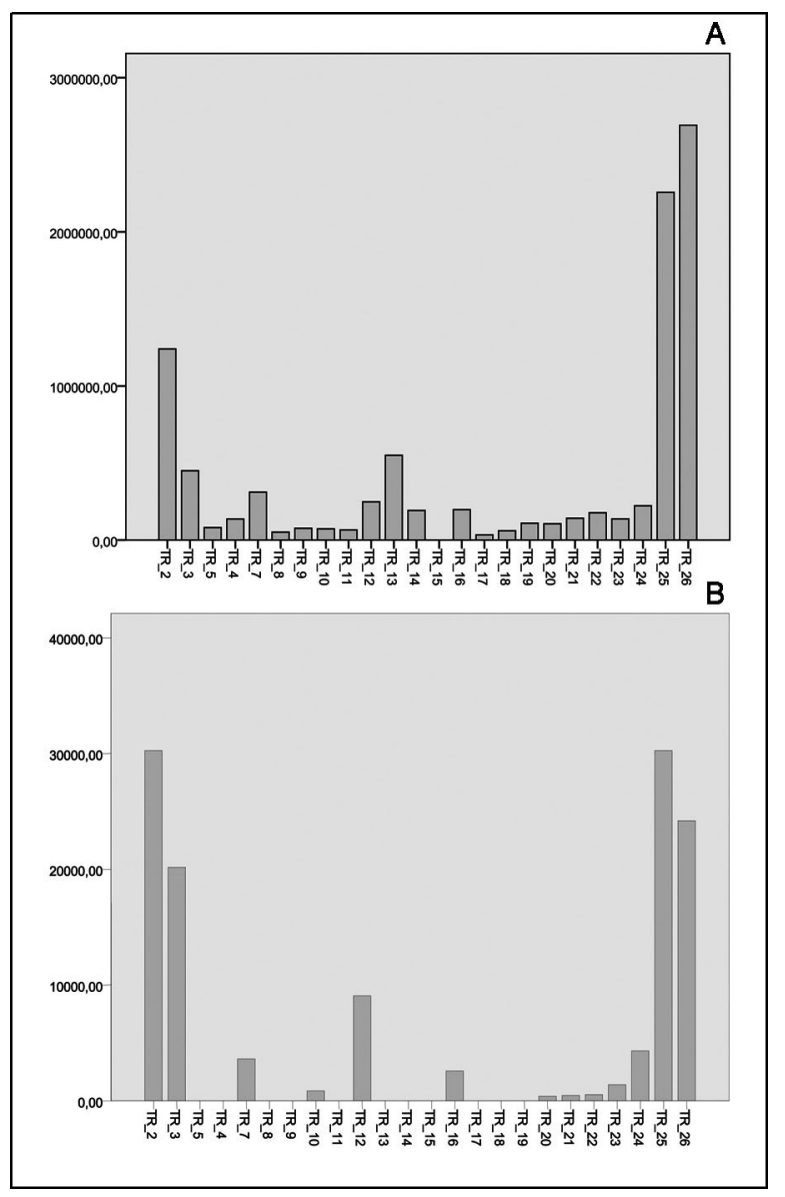

Fig. 4. Trinchera minera de Gorny (TR) (Kargaly, región de Orenburgo, Rusia). En cada muestra de la secuencia A: valores de la concentración polínica (granos de polen por gramo de sedimento). B: valores de concentración de las esporas de Glomus (esporas por gramo de sedimento).

denudación de los suelos vegetales ricos en contenido orgánico y su deposición en la depresión de la trinchera. Nos interesa especialmente el segundo de ellos porque, a tenor de las dataciones $A M S$ de las muestras TR_11, TR_13 y TR_15, es estrictamente contemporáneo de la ocupación Srubnaya de la colina.

Tras la estabilización de las pendientes, se inicia la formación de suelo vegetal dentro de la estructura. Continúa hasta la intervención antrópica masiva representada por la minería de época rusa y la agricultura soviética que vuelven a reavivar la erosión. Ello explicaría las altas concentraciones de polen (y Glomus) de las dos muestras superiores.

\subsection{La lluvia polínica reciente}

Las muestras se seleccionaron para caracterizar las unidades de paisaje en las que se inscriben. Se diseñaron dos áreas de muestreo, sobre las que se definieron sendas retículas cuadradas de $500 \mathrm{~m}$ de paso (Vicent et al. 2000: 55-57) (Fig. 5):

Gorny: $11 \times 4 \mathrm{~km}$ en dirección E-O, centrado en esta colina. Incluye todo el barranco Mijailovski y corta transversalmente el valle del río Usolka.

Novenki: 5,5 $\times 4 \mathrm{~km}$ en torno al poblado de la Edad del Bronce. Comprende la mayoría de la cuenca de recepción del Usolka y sus bordes septentrionales.

De modo independiente y aleatorio se seleccionaron 36 y 19 "unidades de muestreo" (UM) en las áreas de Gorny y Novenki, respectivamente (fracción muestral del $10 \%$ ), a partir de los puntos definidos por círculos de $250 \mathrm{~m}$ de radio inscritos, en las retículas. Los centros geométricos de las UM localizan las "muestras aleatorias" (serie MA). Sus perímetros delimitan los inventarios florísticos y las descripciones de la "verdad terreno".

La localización concreta del muestreo privilegió emplazamientos con suelos estables vegetales no removidos recientemente. Ello exigió a veces desplazar el punto definido por el modelo de muestreo, determinado por GPS. Se mantuvo la localización de las muestras de los emplazamientos situados más de $30 \mathrm{~m}$ en el interior de áreas de cultivo designados por el modelo.

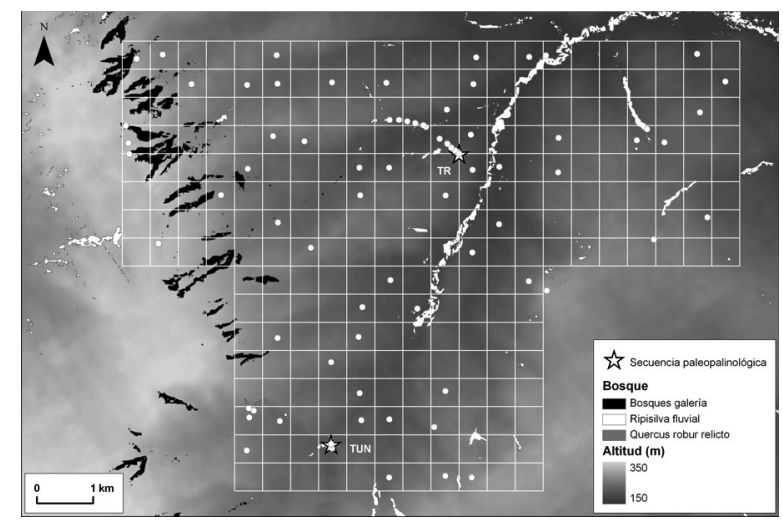

Fig. 5. Distribución de las clases forestales y modelos de muestreo de la lluvia polínica reciente en Kargaly (región de Orenburgo, Rusia). TR: Trinchera minera de Gorny; TUN Turbera de Novenki. 
Se añadieron 9 "muestras opcionales" (serie MO) de lugares de especial interés botánico y 12 alineadas en un transecto y espaciadas $100 \mathrm{~m}$ (serie T1). Este transecto desde el yacimiento Gorny atraviesa el barranco Mijailovski en dirección noroeste. Realizado en la campaña de 1997 investigaba la viabilidad del enfoque. El resto del muestreo se hizo en 1998.

Hemos utilizado las 76 muestras de las tres series sin establecer distinciones entre ellas

\subsection{Periodización de las secuencias}

Las diferencias en la naturaleza y formación de las secuencias plantea problemas a su análisis conjunto. Carecemos de información de la misma calidad para su sincronización. La secuencia de TUN no cuenta con la serie de dataciones disponible para la de TR. En cambio, la cercanía de los dos depósitos a poblados ocupados durante la fase Srubnaya de la Edad del Bronce y el impacto de tales ocupaciones sobre la formación de los sedimentos establecen un cierto nexo, entre ambas series que puede tener sentido analítico (esa fase en Gorny dura unos 400 años, Chernyj 2002d: 125). Dividimos las dos secuencias en torno a los paquetes sedimentarios producidos por los procesos erosivos de origen antrópico en tres segmentos: anterior, contemporáneo y posterior a las ocupaciones de la Edad del Bronce. Por sus características bien diferenciadas se añade una fase reciente, representada por los niveles más superficiales. Así la periodización establecida a partir de la serie TR ordena las muestras de la serie TUN.

Este esquema nos permite estructurar la información palinológica según un modelo temporal coherente. No es tan detallado como para fijar las fechas efectivas de inicio y fin de cada segmento, ni sus duraciones. Pero sí puede ser relacionado con un modelo teórico de transformación del paisaje regional: la ocupación de asentamientos durante el Bronce Final coincide con la máxima expansión de la minería prehistórica.

Hipotéticamente, los bloques de muestras previos a la fase Srubnaya representan el sustrato de paisaje sobre el que actúa el impacto antrópico atribuible a aquella. Según los datos aportados por las dos series, esta Fase 1 tiene su límite inferior en el intervalo 3350-2550 cal BC (base de TUN AA10007) y su final en el intervalo 2300-1960 cal BC (TR_9 AA58666).
La Fase 2 de ocupación de los asentamientos de Novenki y Gorny 1 se identifica en las secuencias con el episodio erosivo detectable en su zona central.

La fecha más antigua de la ocupación Srubna$y a$ de Gorny 1 es OxA5649 (Chernyj 2002d: 126, Tab. 7.1), con un intervalo a $2 \sigma$ de $1950-1600 \mathrm{cal}$ $\mathrm{BC}$, compatible con las primeras dataciones de la Fase 2 de TR, procedentes de la muestra TR_11 (AA58667 y AA58668). El límite superior es más problemático: la fecha más reciente es BM3147, con un intervalo a $2 \sigma$ de $1440-1260$. La ocupación Srubnaya en la colina Gorny se iniciaría por lo tanto entre los siglos XIX y XVII cal BC y cesaría entre los siglos XV y XIII cal BC.

La fecha más reciente del paquete sedimentario relacionado con dicha ocupación es una de las de la muestra TR 13, AA58669, con un intervalo de $2 \sigma$ de 1380-1050 BC (descartando la datación AA50194 $3120 \mathrm{BP} \pm 150$ por su gran desviación típica). El final de este paquete estratigráfico sería, por lo tanto, algo posterior al final del poblado Gorny 1. Este desfase entre ambos fenómenos tiene sentido. El episodio erosivo debió continuar hasta la estabilización de las pendientes y/o la recuperación de la vegetación natural tras el abandono de los asentamientos y el fin de la minería prehistórica.

Sólo disponemos de criterios arqueológicos para aproximar la cronología de la Fase 2 de la serie TUN al correlacionarla con la ocupación del poblado Novenki (sección 3.2). Desconociendo la duración efectiva de la ocupación del poblado sería imprudente atribuir unos límites cronológicos concretos al episodio en la serie TUN. Pero arqueológicamente sabemos que el poblado fue ocupado con la intensidad que atestiguan las construcciones permanentes de piedra, durante la fase Srubnaya clásica. Esta, en Gorny 1, corresponde al intervalo 1900-1300 cal $\mathrm{BC}$, resultante de la combinación de las 17 fechas del poblado (Chernyj y Martínez Navarrete 2005: Fig. 9). Es razonable asumir, entonces, que la posición estructural de la Fase 2 en TUN equivale a la de su homónima en la serie TR, aunque los intervalos cronológicos concretos no coincidan en su totalidad.

El contenido palinológico de las muestras asignadas a esta fase representaría un proceso de intervención antrópica intensa en el entorno de los depósitos, pero es imposible su reconstrucción precisa. Las inconsistencias internas de la 
serie de dataciones de TR, atribuidas al arrastre y mezcla de paleosuelos del entorno, exigen incluir estas consideraciones tafonómicas en el análisis.

La Fase 3 representa el período subsiguiente al abandono de los asentamientos Srubnaya y fin de las operaciones mineras prehistóricas en la región. En la serie TR comienza la formación in situ de chernozem, lo cual le da un carácter fuertemente contrastante con la fase anterior. En la serie TUN se recupera el régimen de sedimentación previo a la perturbación de la Fase 2. Ahora bien, los valores altos constantes de Glomus (secciones 3.2 y 3.3) indican que el depósito recibe aportes de sedimento superficial de un entorno en el que siguen activos procesos de erosión.

La fecha más antigua para esta fase (TR 17 AA58674), con un intervalo de $2 \sigma$ de $1000-\overline{8} 20$ cal $\mathrm{BC}$, es compatible con la datación más tardía de la fase anterior. La posición estratigráfica de la fecha más reciente (TR_23 AA58677), con un intervalo $600-770 \mathrm{cal} \mathrm{AC}$, es coherente con su valor y descarta AA58676. Este período de casi dos milenios tiene una cierta coherencia desde el punto de vista histórico. Tras la fase Srubnaya, no se constatan asentamientos permanentes pero sí un kurgan sármata equidistante unos $3 \mathrm{~km}$ de ambos depósitos (Chernyj et al. 2002: 74-75). Lo que conocemos para la estepa del Ural es una ocupación por poblaciones nómadas durante la Edad del Hierro y en tiempos históricos. Las considerables diferencias culturales entre ellas no afectarían su interacción con el medio hasta su anexión al imperio ruso a mediados del siglo XVIII d.C., inicio de la fase moderna de la minería de Kargaly. Los arqueólogos rusos les atribuyen unas bases económicas netamente pastoriles. Su acción sobre el entorno sería, por lo tanto, similar durante toda la Fase 3, sin excluir cambios en la escala de la incidencia, según la intensidad del pastoreo en cada período histórico. En un análisis más detallado, esas diferencias podrían dar cuenta de la variabilidad interna de los espectros polínicos asignados a esta fase sin afectar sus líneas generales.

Cabe suponer, pues, que la Fase 3 concluyera con la reanudación de las operaciones mineras en el coto de Kargaly, en torno a 1750 d.C. La minería de época rusa se desarrolla en la zona entre esta fecha y los primeros años del siglo XX. Su elevada intensidad ha configurado el paisaje actual. La colina Gorny fue parte del distrito minero de Mijailovski. La conservación del poblado
Gorny 1 atestigua que la meseta superior no fue perforada. En cambio, su pertenencia al mismo se refleja en la construcción rusa sobre la trinchera y en el incremento espectacular de la concentración polínica y de los valores de Glomus en las dos muestras mas superficiales de la serie TR. Refuerzan la interpretación propuesta para estas variables tanto esos contenidos como, a la inversa, que en la serie TUN, no se observe este efecto, como corresponde a un área al margen de las operaciones mineras. La concentración polínica de la muestra más superficial (TUN_0) apenas supera la de las anteriores, y el nivel de Glomus es similar. El fondo de la cuenca de recepción del Usolka debió de ser una buena reserva de pastos de verano, y como tal usada con intensidad durante la Fase 3. Este uso continúa en la actualidad, aunque la construcción de un embalse en época soviética inundó una gran parte. Al responder al mismo régimen de formación y a un grado similar (aunque de intensidad creciente) de impacto antrópico local, las muestras superficiales no se individualizan en la serie.

El final de la Fase 3 puede fijarse en la segunda mitad del siglo XVIII d.C. Pero las muestras claramente asignables en TUN y TR a esta fase son insuficientes para el análisis estadístico. La caracterización del paisaje mediante el muestreo de la lluvia polínica reciente completa la base empírica exigida por nuestro modelo experimental.

El paisaje actual de Kargaly está configurado por dos etapas sucesivas: la minería rusa del cobre (1750-c. 1900 d.C.) y la agricultura planificada soviética (c. 1950-1991 d.C.). Especialmente la segunda ha afectado significativamente la conservación del suelo vegetal. Las muestras representan toda la Fase 4, sin que sea posible distinguir si contienen sedimentos del período ruso, del soviético o una mezcla de ambos.

\section{LOS BOSQUES DE KARGALY}

Gran parte del esfuerzo durante el desarrollo del proyecto Kargaly se dedicó a describir en detalle los elementos geográficos y bióticos del paisaje regional y a obtener también datos cuantitativos sobre las distribución de estos mismos elementos, susceptibles de permitir la modelización factorial del paisaje (Vicent et al. 2000). La metodología se articuló en torno a un programa 
de teledetección espacial, combinado con un reconocimiento directo del terreno y un inventario florístico (D’Antoni y Spanner 1993; Vicent et al. 2006; López-Sáez 2002).

El objetivo del programa de teledetección fue la cartografía temática del territorio de Kargaly para establecer la distribución de las cubiertas, ocupaciones y usos del suelo en el área de estudio. Los datos radiométricos básicos combinan tres imágenes: una Landsat $5 \mathrm{TM}$ de septiembre de 1994, que representa el estado de la "verdad terreno" documentado en el trabajo de campo, y dos imágenes Aster TERRA de junio de 2002 y julio de 2004. La resolución espacial de $30 \mathrm{~m}$ de los datos TM se mejoró fusionando esa imagen con la Aster TERRA de julio de 2002 (15 m de resolución). El resultado de la fusión se sometió a una clasificación supervisada a partir de las observaciones de campo. Su objetivo era informar la "verdad terreno" mediante inventarios florísticos, descripciones normalizadas del terreno, fotografías, etc., realizados durante las campañas de 1995, 1997 y 1998.

El programa de teledetección permitió separar las cubiertas forestales y caracterizar de forma general las variaciones en su composición y densidad (D'Antoni y Spanner 1993; Vicent et al. 2000; Vicent et al. 2006). La figura 5 presenta una versión simplificada de esta cartografía. La estepa arbolada de Kargaly es representativa de la que constituye el borde septentrional de la Gran Estepa Euroasiática. La topografía local es de colinas suaves y barrancos organizados en torno al valle del río Usolka al Este y una dorsal que separa las cuencas del Volga y el Ural al Oeste. Las altitudes oscilan entre los 350 m.s.n.m. de esta última y los 150 m.s.n.m. en el punto más bajo del territorio. El paisaje está dominado casi por completo por la estepa, una formación de herbáceas relativamente compleja. Las reducidas extensiones boscosas se alinean, en general, siguiendo los cursos de agua. El del Usolka, poco caudaloso, que recorre el área de estudio en dirección norte, es el único permanente. En sus márgenes existe un estrecho bosque ripario, muy antropizado, con sauces, chopos y, más raros, alisos, fresnos, olmos y arces. Fuera de esto, la superficie arbolada se distribuye en pequeños bosques galería siguiendo los barrancos por los que circula el agua del deshielo o, en sus cabeceras, sobre la divisoria de aguas. Ocasionalmente, algunos alcanzan la ladera de un interfluvio. Hoy en día están casi íntegramente constituidos por abedul (Betula pendula) $\mathrm{y}$, en sus bordes exteriores o colonizando zonas incendiadas, álamo temblón (Populus tremula). En la zona más húmeda hay sauces ( $\mathrm{Sa}$ lix sp.) y, rara vez, tilos (Tilia sp.) y serbales (Sorbus aucuparia).

El roble (Quercus robur) es muy escaso. Se circunscribe a unas decenas de ejemplares situados en el área de Novenki, en el interior de un bosque mayoritariamente compuesto por abedules y álamos temblones, asentado sobre la ladera que marca el límite noroccidental de la cuenca de recepción del Usolka (ver Fig. 5). Fuera de ellos hay formaciones arbustivas, con predominio de algunas Rosaceae y espino cerval (Rhamnus cathartica). Suelen colonizar las zonas alteradas por la minería reciente.

En resumen: las asociaciones de especies leñosas que ocupan unidades de paisaje bien definidas son:

(1) Ripisilva fluvial siguiendo las orillas del río Usolka.

(2) Bosques galería, a lo largo de los cauces de los barrancos y en sus cabeceras.

(3) Matorral espinoso en las áreas mineras situadas en laderas e interfluvios de los barrancos.

Las dos primeras por su extensión y densidad pueden ser identificadas en las imágenes de satélite. La ligera diferencia en sus características espectrales permitió separarlas en dos clases en el proceso de clasificación (Fig. 5). La tercera asociación y los ejemplares aislados sólo pudieron ser identificados en los inventarios y descripciones de la "verdad terreno", por lo que no se incluyen en la figura.

En la actualidad, la mayoría del territorio está configurado por estrategias de explotación agropecuaria extensiva, típicas de la agricultura soviética. El área de estudio se reparte entre dos empresas agrícolas, correspondientes al antiguo Sovjoz de Uranbash y al antiguo Koljoz de Komissarovo. Grandes parcelas sembradas con cereales, en rotación con maíz, girasol y, en menor medida, alforfón, entre otros cultivos, ocupan el $63 \%$ del territorio. En torno a un tercio de las parcelas está en barbecho. Era una agricultura de bajo rendimiento y alto riesgo de fracaso, basada en una mecanización a gran escala. Su efecto masivo sobre la distribución de los bosques galería, ocupando vaguadas que anteriormente debieron albergarlos, queda atestiguado por los que todavía subsisten y por los ejemplares aislados de 
abedul o sauce. Las concentraciones de obras mineras limitaban la expansión de los cultivos mecanizados. A veces, los abedules colonizan los pozos. Pero en ningún caso este bosque secundario puede haber compensado la pérdida de superficie forestal.

Un $32 \%$ del área de estudio está ocupada por pastizales empleados en una ganadería extensiva predominantemente bovina. Esta actividad mediatiza la vegetación natural de estepa. En las zonas más húmedas, donde la formación de herbáceas lo permite, se siega la estepa para producir heno. Esta práctica, sin duda, ha contribuido a la delimitación de las áreas boscosas. Se puede decir que los bosques de Kargaly se distribuyen en los intersticios de un paisaje agrario socialista. El bosque mismo es objeto de explotación. Los diámetros de la mayoría de los pies de abedul son inferiores a $50 \mathrm{~cm}$, denotando un ciclo regular de tala. Los procesos de recolonización, tras los frecuentes incendios, pueden haber favorecido a ciertas especies.

\subsection{La lluvia polínica reciente y el paisaje actual}

La cubierta forestal se compone de contadas especies de árboles y arbustos. La serie de muestras de la lluvia polínica reciente, cuyo entorno conocemos gracias a la cartografía forestal y las descripciones e inventarios de la vegetación, informa sobre el modo como el registro palinológico representa la distribución efectiva de las especies forestales en el área de trabajo.

En la tabla 3 aparecen los principales parámetros de la distribución en la serie de las proporciones de los palinomorfos del grupo (A), en orden decreciente de sus promedios. Cabe interpretar estos parámetros como una estimación de la probabilidad de que un palinomorfo extraído al azar de una muestra obtenida en un punto del territorio, escogido también al azar, pertenezca a un taxón o grupo dados. En este sentido pueden aproximarnos al peso relativo de cada uno en el registro polínico producido por el paisaje actual.

La distribución de la variable "Total de Arbóreas" (Fig. 6) expresa por lo tanto la variabilidad del balance entre estas y el resto de los palinomorfos, fundamentalmente herbáceos. La distribución tiene un acusado sesgo: el $50 \%$ de las muestras tienen menos de un 10,82 \% de arbóreas, y el $75 \%$ menos de $14,89 \%$. Como puede verse en la figura 7 las muestras que superan este valor se han obtenido en formaciones forestales o en un área muy próxima. Esta estructura refleja el carácter estepario del área de trabajo, y la marginalidad de las reducidas superficies forestales.

Los valores recogidos en la tabla 3 demuestran la gran variabilidad local entre emplazamientos en la representación de cada taxón. El hecho de que ninguno aparezca en todas las muestras y

\begin{tabular}{|l|c|c|c|c|}
\hline & Mínimo & Máximo & Media & $\begin{array}{c}\text { Desviación } \\
\text { típica }\end{array}$ \\
\hline Total Arbóreas &, 41 & 71,62 & 13,6766 & 12,47522 \\
Betula &, 00 & 62,16 & 4,9845 & 8,82697 \\
Populus &, 00 & 12,43 & 2,6933 & 2,35382 \\
Quercus &, 00 & 13,99 & 1,6964 & 2,12515 \\
Rosaceae &, 00 & 13,17 & 1,3342 & 2,38413 \\
Alnus &, 00 & 6,34 &, 7070 &, 92342 \\
Prunus $\mathrm{t.}$ &, 00 & 13,17 &, 6341 & 2,03439 \\
Salix &, 00 & 7,93 &, 5061 & 1,21440 \\
Ulmus &, 00 & 2,44 &, 2490 &, 46430 \\
Tilia &, 00 & 10,73 &, 2445 & 1,28023 \\
Acer &, 00 & 2,22 &, 1995 &, 45267 \\
Fraxinus &, 00 & 2,93 &, 1494 &, 38906 \\
Rhamnus &, 00 & 2,65 &, 0679 &, 36406 \\
Sambucus &, 00 & 1,83 & &, 27010 \\
N=76 & & & \\
\hline
\end{tabular}

Tab. 3. Estadísticos descriptivos de los taxones polínicos del grupo (A) (\% sobre la suma base), en la Fase 4, en orden decreciente de sus promedios (Kargaly, región de Orenburgo, Rusia). 


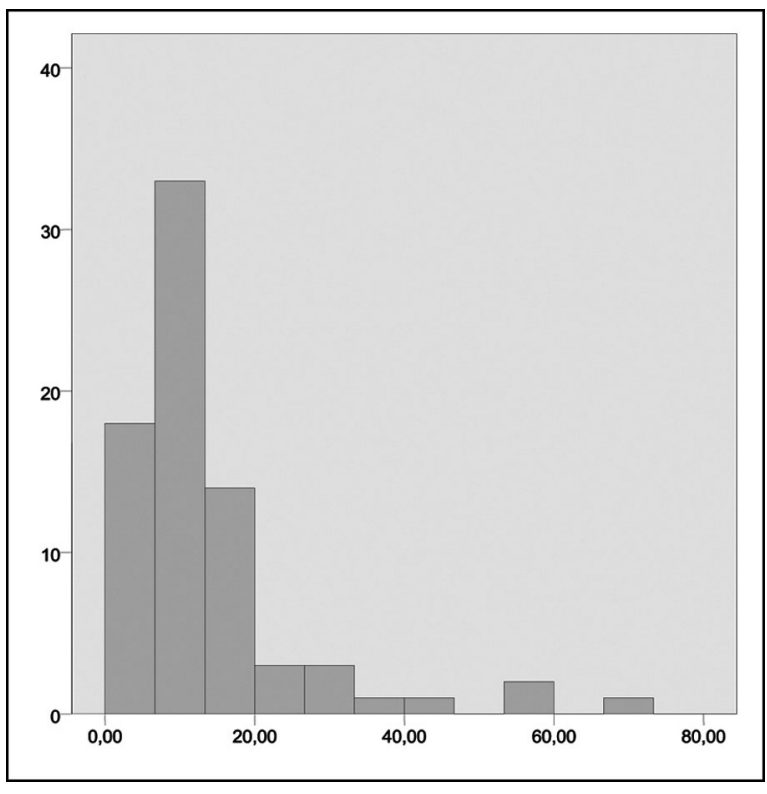

Fig. 6. Lluvia polínica reciente: distribución de la variable "Total de Arbóreas" (\% sobre la suma base) (Kargaly, región de Orenburgo, Rusia). Media $=13,68$; Desviación típica $=12,475 ; \mathrm{N}=76$.

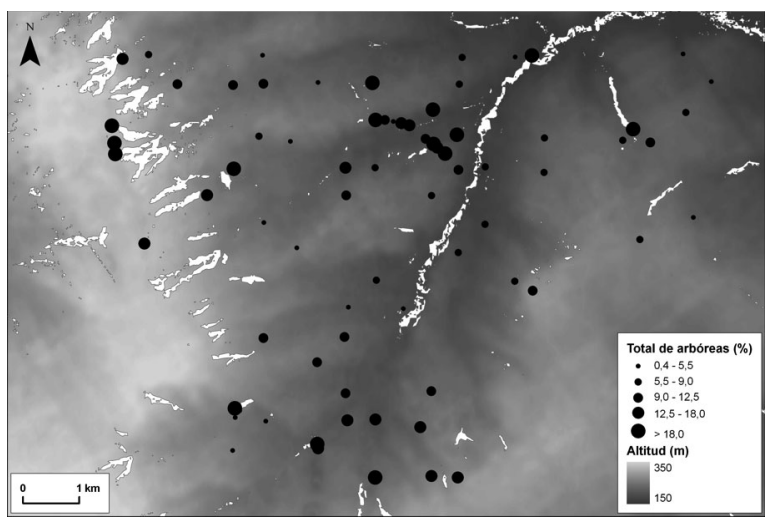

Fig. 7. Distribución espacial de la variable "Total de Arbóreas" (\% sobre la suma base) en la lluvia polínica reciente (Kargaly, región de Orenburgo, Rusia).

los valores máximos ocasionalmente altos, en particular de Betula, Populus, Quercus y Prunus t., indican que la proximidad a los retazos forestales, e incluso a ejemplares singulares, es un factor muy determinante en la representación palinológica, y que estas especies no dispersan a nivel regional. Este carácter fuertemente local de la representación palinológica de las leñosas no impide que pueda modelizarse en parte, mediante herramientas de análisis SIG. El agregado de da- tos en su conjunto puede relacionarse con algunos factores que explican condiciones generales del paisaje que permiten construir agrupaciones significativas de muestras.

La distribución de los palinomorfos es coherente en primera instancia, con las observaciones sobre "la verdad terreno". En la matriz de correlaciones entre los taxones (Tab. 4) estos se asocian a tenor de los tres tipos principales de formaciones forestales del área. Los taxones que las componen según los inventarios florísticos muestran correlaciones significativas entre sí y no con el resto. Este criterio permite elaborar un inventario de las especies asociadas:

(1) Ripisilva fluvial: Acer, Alnus, Fraxinus, Salix, Ulmus.

(2) Bosques galería: Betula, Populus, Sambucus, Tilia.

(3) Matorral espinoso: Prunus t., Rosaceae, Rhamnus.

Sólo Quercus carece de correlación significativa, reflejando la excepcionalidad de su distribución actual, circunscrita a unas decenas de ejemplares en el área de Novenki, en un bosque compuesto, en su mayoría, por abedules y álamos temblones. La muestra MO_7 obtenida en su interior contiene un 13,99\% de polen de Quercus. No obstante, el polen de esta especie sólo falta en 13 muestras de las 76 del grupo de control $(17,1 \%)$, aunque su porcentaje es en general muy bajo. Esta extensa distribución no es explicable por la difusión directa a partir del relicto, un hecho que se valorará más adelante.

El conjunto de factores que determinan la dispersión del polen (movilidad y productividad polínicas) y la posición de los emplazamientos muestreados (orientación de los vientos dominantes, obstáculos naturales para la difusión del polen...) explican que los coeficientes sean en general bajos.

Las ambigüedades taxonómicas, por su parte, dan cuenta de algunas anomalías: la correlación significativa entre Tilia y Rosaceae se explica por la presencia de Sorbus aucuparia, clasificada en este último grupo, en algunos bosques galería.

Pese a estas limitaciones, la estructura de la matriz de correlaciones describe bien cómo las diferentes especies se asocian en el territorio. Este resultado fundamentará el análisis comparativo de los datos paleopalinológicos y la lluvia polínica reciente. 


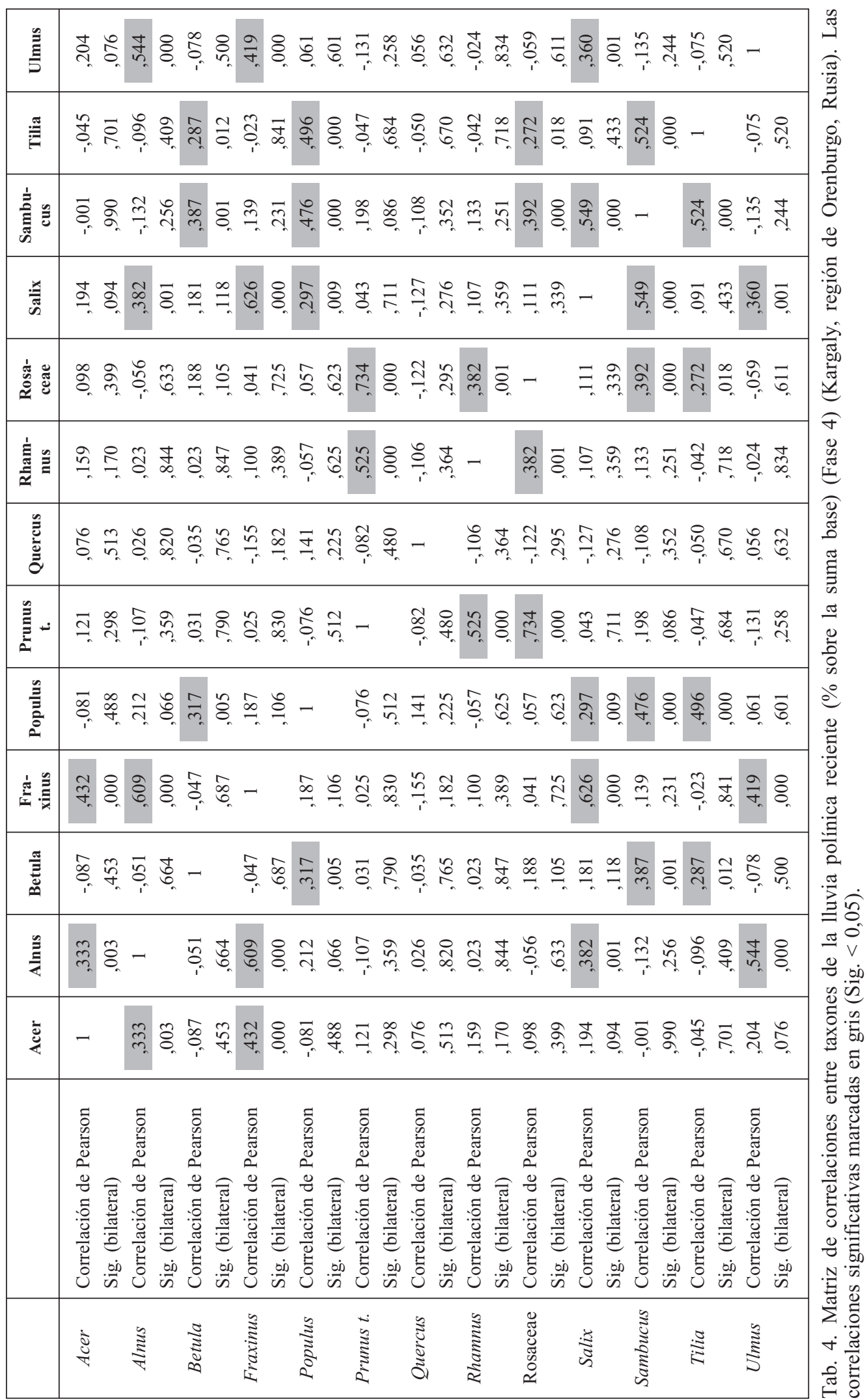

T. P., 67, N. ${ }^{\circ} 2$, julio-diciembre 2010, pp. 511-544, ISSN: 0082-5638 doi: $10.3989 /$ tp.2010.10054 


\section{ANÁLISIS DE LOS DATOS PALEOPALINOLÓGICOS}

Todas las especies identificadas en la lluvia polínica reciente y los inventarios florísticos están en las muestras paleopalinológicas. Cambian las proporciones. Es decir, la composición por especies del bosque no habría variado con el tiempo, pero sí su estructura cuantitativa.

La estructura de los datos disponibles se resiente al corresponder las dos secuencias a emplazamientos singulares. Los espectros polínicos representan la distribución de la vegetación a una escala local, cuyo ámbito no es determinable de modo efectivo por depender de factores geográficos. Las secuencias, por lo tanto, informan sobre puntos concretos del territorio a lo largo del tiempo. Las muestras de la lluvia polínica reciente, por el contrario, describen palinológicamente la variación de la vegetación en el conjunto del territorio. Si comparamos unos datos y otros interpretamos esos cambios en términos de morfología del paisaje en relación con las condiciones específicas de localización de cada muestra.

La estrategia de análisis tiene dos etapas:

(1) análisis diacrónico de las variaciones en la concentración de polen de las secuencias. Se trata de establecer si hay cambios significativos entre los distintos episodios de formación del depósito. No se compararán los valores concretos de concentración para cada muestra, sino los agregados de muestras correspondientes a las distintas fases.

(2) análisis comparativo de las muestras paleopalinológicas con las de la lluvia polínica reciente. Se busca fijar los mejores análogos actuales de las primeras a partir de las muestras del grupo de control, cuyos entornos conocemos.

La similitud se establecerá a partir del análisis cuantitativo de las distribuciones de las frecuencias relativas respecto a la suma base de los taxones indicadores de las cubiertas forestales.

\subsection{Análisis diacrónico}

La concentración de polen, expresada en número de granos por gramo de sedimento, permite evaluar independientemente las variaciones absolutas de cada taxón en las fases de la misma secuencia. Ello requiere que las condiciones tafonómicas sean estables. El supuesto se cumple en relación con las condiciones que dependen de la posición de las muestras, pero no necesariamente respecto a los mecanismos de formación del depósito. En TR y TUN las perturbaciones en esos mecanismos afectan especialmente a la Fase 2 de ocupación Srubnaya. Ello nos obliga a limitar la comparación a ciertas fases que se especificarán en cada caso.

Las posibles estrategias de análisis cuantitativo están muy limitadas por el escaso número de muestras de cada fase de las secuencias y por la dificultad de asumir algunos supuestos básicos de los modelos estadísticos, como la normalidad de las distribuciones. Por ello utilizaremos, en general, técnicas de análisis no paramétrico, aplicables con series pequeñas de datos y/o datos para los que no pueda asumirse normalidad.

El objetivo de la comparación es, como se dijo, determinar si hay cambios significativos entre las fases. La interpretación de los valores de concentración en términos de distribución efectiva de la vegetación es más problemática. Carecemos de datos sobre la productividad de polen de cada especie, su movilidad específica y la forma y dimensiones de la cuenca de captación del depósito. Pero podemos asumir que la relación entre cantidad de polen y número de ejemplares productores de polen de una especie determinada es una función que, sea o no lineal, es idéntica para todas las fases estudiadas. Consideramos, entonces, que cambios significativos en la concentración indican cambios en la distribución de la especie o especies productoras. Consecuentemente, la concomitancia en las variaciones de distintos taxones define distintos estados de la cubierta arbórea en el entorno del depósito.

\subsection{Turbera de Novenki (TUN)}

El depósito higroturboso de Novenki ocupa el fondo del valle principal del río Usolka, en el punto en el que la convergencia de varios cursos estacionales de agua determina el nacimiento del río. En la actualidad un embalse anega en parte la zona. La vegetación en el entorno inmediato se reduce a una formación de sauces de porte arbustivo, rodeados de pastos intensivamente explotados por la ganadería local. Esta área húmeda es una buena reserva de pasto de verano en un entorno sumamente árido. Como se ve en la figura 5, las formaciones boscosas están en los bordes de la cuenca a más de $750 \mathrm{~m}$ del punto de muestreo. 
El mecanismo normal de formación del sedimento en un depósito higroturboso es la captación de polen a través de un interfaz de agua en reposo. Este mecanismo se vio alterado por el episodio erosivo que da lugar al paquete estratigráfico de la Fase 2. Hemos asumido que las altas concentraciones de polen provienen del arrastre de sedimentos provocado por la denudación de los suelos en el entorno del punto de muestreo. Ello exige reducir la comparación a las muestras anteriores y posteriores a este episodio, que hemos delimitado a partir del rango de variación de la concentración total y de la presencia de Glomus. La coyuntura de cambio Fase 1 / Fase 3 debe reflejar el impacto de la ocupación Srubna-

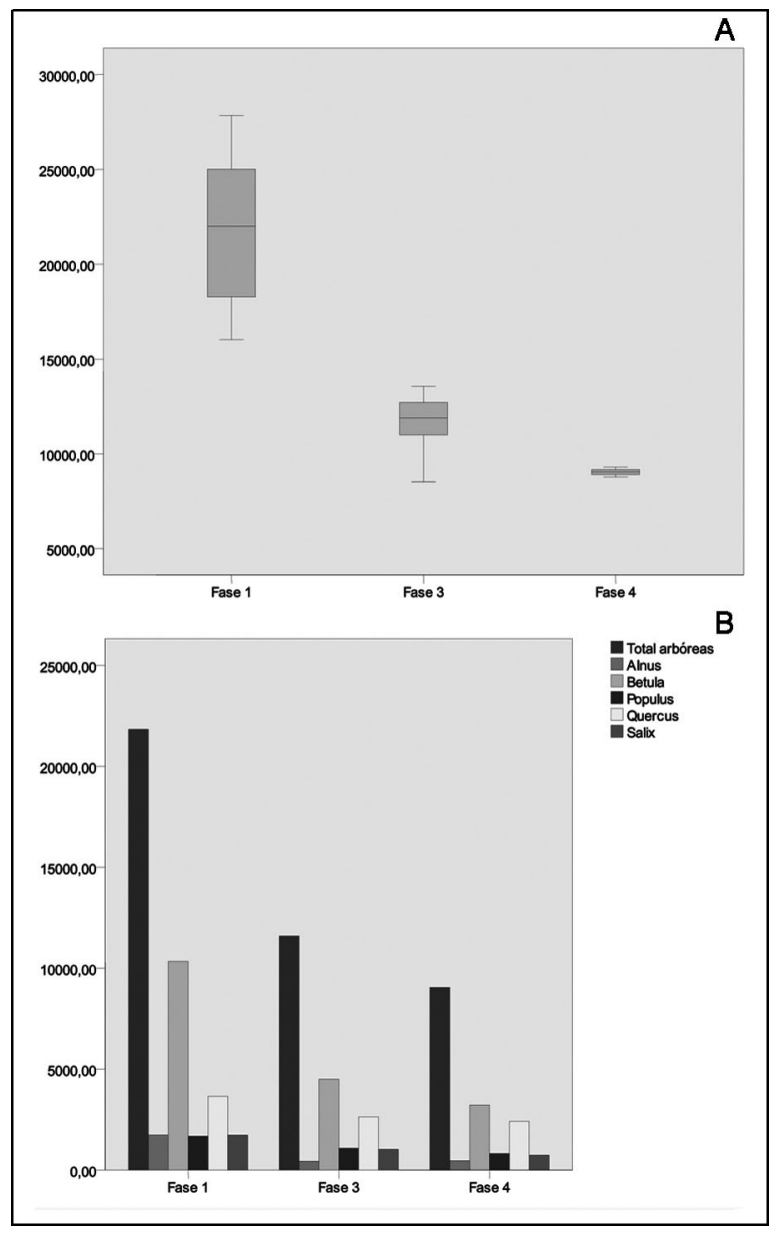

Fig. 8. Secuencia de la Turbera de Novenki (TUN) (Kargaly, región de Orenburgo, Rusia). A: distribución por fases de la concentración de la variable "Total de Arbóreas", excluida la Fase 2 (granos de polen por gramo de sedimento) B: variación por fases de la media de la concentración de los taxones mayoritarios. ya del área, mientras que la de la Fase 3 / Fase 4 registrará las transformaciones recientes. Faltando por completo los indicios de minería, ambas coyunturas se remiten al impacto de los cambios en las prácticas agropastoriles.

La figura 8A representa la distribución por fases de la concentración de la variable "Total de Arbóreas", una vez excluida la Fase 2. La figura 8B muestra la variación por fases de la media de la concentración de los principales taxones. Considerando en conjunto las tres fases analizadas el efecto de la clasificación es significativo según el test de Kruskal-Wallis, análogo no paramétrico del análisis de la varianza (Tab. 5), tanto en lo que se refiere a la variable agregada "Total de Arbóreas" como a los principales taxones, con excepción de Ulmus, Prunus, Acer, Fraxinus y Rosaceae. La variable "Concentración total" no presenta diferencias significativas, lo que ratifica la pertinencia de la hipótesis de selección de fases, mientras que la variable "Total de Arbóreas" sí. En resumen, las diferencias absolutas en los rangos de variación por fases de la cantidad de polen de arbóreas y los principales taxones incluidos en este grupo son demasiado grandes para deberse al azar. Podemos concluir que los datos de cada grupo provienen de diferentes distribuciones. Trasladando esto al contexto empírico que nos ocupa concluimos que la secuencia muestra

\begin{tabular}{|l|r|r|r|}
\hline & $\chi^{2}$ & gl & $\begin{array}{c}\text { Sig. } \\
\text { asintót. }\end{array}$ \\
\hline Concentración total & 0,817 & 2 & 0,665 \\
Total arbóreas & 0,029 & 2 & 0,007 \\
Acer & 1,907 & 2 & 0,385 \\
Alnus & 6,164 & 2 & 0,046 \\
Betula & 10,029 & 2 & 0,007 \\
Fraxinus & 5,084 & 2 & 0,079 \\
Populus & 8,069 & 2 & 0,018 \\
Prunus t. & 5,084 & 2 & 0,079 \\
Quercus & 7,789 & 2 & 0,02 \\
Rhamnus & 6,177 & 2 & 0,046 \\
Rosaceae & 0,352 & 2 & 0,839 \\
Salix & 11,339 & 2 & 0,003 \\
Sambucus & 9,478 & 2 & 0,009 \\
Tilia & 6,24 & 2 & 0,044 \\
\hline
\end{tabular}

Tab. 5. Turbera de Novenki (TUN) (Kargaly, región de Orenburgo, Rusia): resultados de la aplicación de la prueba de Kruskal-Wallis a la distribución de la variable "Total de Arbóreas" (\% sobre la suma base) en las Fases 1, 3 y 4. Gl: grados de libertad; Sig; asintót.: significación asintótica. 
cambios significativos en la densidad y composición de la cobertura arbórea en el entorno de TUN.

La comparación de las fases pre- y post-Srubnaya (1 y 3 respectivamente) expresa los cambios producidos en el entorno entre la etapa anterior a la ocupación Srubnaya y la fase posterior a su final, como consecuencia de la intensa antropización del área que suponemos durante la Fase 2. Destaca la drástica disminución del volumen total de polen arbóreo. El promedio de polen de arbóreas locales por gramo de sedimento en la fase pre-Srubnaya es casi el doble que en la fase post-Srubnaya (concretamente 1.7 veces mayor). Una parte importante de esta disminución se debe a Betula. Su promedio es el $47 \%$ de la media del total de arbóreas en la Fase 1 y el $39,45 \%$ en la Fase 3, pero pasa de ser el $27 \%$ del total de palinomorfos al $12 \%$. Su curva es prácticamente paralela a la del total de arbóreas (Fig. 8B). El estadístico U de Mann-Whitney (Tab. 6A) muestra que las diferencias entre los taxones mayoritarios son significativas con la excepción de Populus.

Los cambios entre las fases 3 y 4 son también notables, aunque algo menos acusados: la diferencia para la variable "Total de Arbóreas", cuya media es 1.3 veces más pequeña que la de la fase anterior, es significativa, según el mismo test (Tab. 6B) La situación de los taxones mayoritarios, individualmente considerados, es algo diferente a la que observamos en la anterior coyuntura: la diferencia es significativa en Populus pero no en Quercus ni Alnus. Betula sigue explicando la mayoría de la variación entre fases: su valor continúa representando una proporción similar del promedio del total de arbóreas (35\%) que en la fase anterior pero pasa a ser sólo el 8,4\% del total de palinomorfos.

En conclusión, el depósito TUN muestra un proceso de disminución significativa e irregular de la concentración agregada de polen arbóreo a lo largo de las fases de la secuencia. Este proceso se debe en gran parte al retroceso del peso del abedul, y afecta de forma diferente al resto de los taxones. Una valoración general de los datos debe incidir en dos aspectos:

(1) la secuencia muestra una pérdida constante de la importancia de los taxones arbóreos en las dos coyunturas analizadas, es decir, las causas del retroceso de las arbóreas son eficientes a lo largo de todo el proceso histórico.

\begin{tabular}{|l|c|c|c|c|}
\hline \multicolumn{1}{|c|}{ A } & $\begin{array}{c}\text { U de } \\
\text { Mann- } \\
\text { Whitney }\end{array}$ & $\begin{array}{c}\text { W de } \\
\text { Wilcoxon }\end{array}$ & $\mathbf{Z}$ & $\begin{array}{c}\text { Sig. } \\
\text { asintót. } \\
\text { (bilateral) }\end{array}$ \\
\hline Concentración total & 14 & 35 & $-0,183$ & 0,855 \\
Total arbóreas & 0 & 21 & $-2,739$ & 0,006 \\
Acer & 12 & 33 & $-0,548$ & 0,584 \\
Alnus & 3 & 24 & $-2,191$ & 0,028 \\
Betula & 0 & 21 & $-2,739$ & 0,006 \\
Fraxinus & 8 & 23 & $-1,278$ & 0,201 \\
Populus & 4 & 25 & $-2,008$ & 0,045 \\
Prunus t. & 6 & 27 & $-1,643$ & 0,1 \\
Quercus & 3 & 24 & $-2,191$ & 0,028 \\
Rhamnus & 3 & 24 & $-2,196$ & 0,028 \\
Rosaceae & 12,5 & 33,5 & $-0,581$ & 0,562 \\
Salix & 0 & 21 & $-2,745$ & 0,006 \\
Sambucus & 0 & 21 & $-2,745$ & 0,006 \\
Tilia & 6 & 27 & $-1,643$ & 0,1 \\
Ulmus & 8 & 29 & $-1,281$ & 0,2 \\
\hline \multicolumn{1}{|c|}{ B } & U de & W de & $\mathbf{Z}$ & Sig. \\
asintót. \\
(bilateral)
\end{tabular}

Tab. 6. Turbera de Novenki (TUN) (Kargaly, región de Orenburgo, Rusia): resultados de la aplicación de la prueba del estadístico U de Mann-Whitney a la distribución de la variable "Total de Arbóreas" y los taxones mayoritarios ( $\%$ sobre la suma base). A: Fases 1 y 3. B: Fases 3 y 4. Sig. asintót.: significación asintótica.

(2) la tasa de cambio parece mayor en los taxones claramente riparios (Betula, Alnus) que en los menos dependientes de los cursos de agua (Quercus, posiblemente Populus).

Este último hecho, refleja posiblemente dos componentes espaciales en el registro: uno local (la mayor parte del polen del primer grupo) y otro supralocal (el polen de taxones de dudosa implantación local, como Quercus). A partir de esta hipótesis, interpretamos la diferente tasa de cambio entre estos dos grupos a resultas de factores que actúan de forma más intensa en el entorno local que en el conjunto del territorio. Sabemos que no se vinculan con la explotación cuprífera prehistórica. 


\subsection{Trinchera minera de Gorny (TR)}

La colina Gorny es el final de un interfluvio y se eleva unos $50 \mathrm{~m}$ sobre el valle principal. El entorno es estepario con pequeñas colonias de abedules y algunas formaciones arbustivas. Desde la trinchera se ve el barranco Mijailovski al $\mathrm{N}$ y el valle principal del río Usolka al E.

El análisis de la concentración polínica en TR plantea problemas específicos por la heterogeneidad del proceso de formación de los sedimentos. Alternan episodios de formación natural de suelo con procesos erosivos. Esta estructura impide usar todas las secciones cronoestratigráficas en una comparación cruzada. El rango de variación

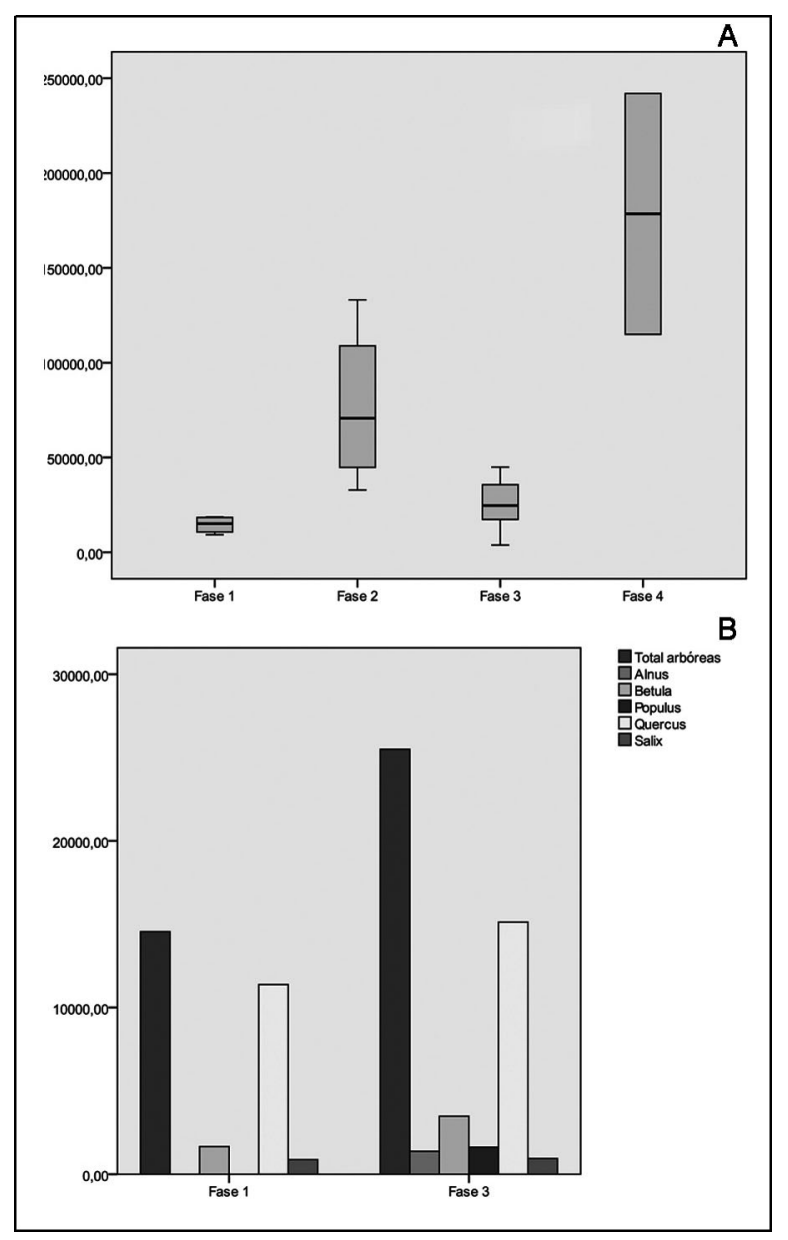

Fig. 9. Secuencia de la Trinchera minera de Gorny (TR) (Kargaly, región de Orenburgo, Rusia). A: Distribución por fases de la concentración de la variable "Total de Arbóreas" (granos de polen por gramo de sedimento). B: variación por fases de la media de la concentración de los taxones mayoritarios. en la concentración de arbóreas en las Fases 2 y 4 es muy superior al de las Fases 1 y 3 (Fig. 9A). Las descartamos al resultar de episodios de colmatación de la trinchera con depósitos erosivos. Limitaremos la comparación a las Fases 1 y 3 en lo que se refiere a la valoración de la concentración de polen.

El análisis de la coyuntura Fase 1 / Fase 3 revela importantes diferencias con la secuencia anterior. Los valores de concentración de TR se mueven en rangos similares a los de TUN y son estadísticamente equivalentes en ambas fases, sin diferencias significativas en la distribución de la variable total de arbóreas entre ellas (Fig. 9B y Tab. 7). En cambio, la composición por taxones es totalmente diferente a la observada en TUN. Faltan Populus y Alnus en la Fase 1, así como varios taxones minoritarios que sí aparecen en la Fase 3: Acer, Ulmus, Fraxinus y Sambucus. La jerarquización de los demás taxones es completamente distinta. Sobresale Quercus con un promedio del $78 \%$ de la media del total de arbóreas en la Fase 1 y del $54 \%$ en la 3. Sin embargo el primer valor sólo representa el $17 \%$ del promedio del total de palinomorfos y el segundo el $12 \%$. Pese a estas diferencias en el peso relativo, las variaciones absolutas de Quercus agregadas por fases no son estadísticamente significativas, según el test de Mann-Whitney (Tab. 7). Es decir, de acuerdo con la hipótesis de trabajo, la densidad de robles en el entorno del depósito es estadísti-

\begin{tabular}{|l|c|c|c|c|}
\hline & $\begin{array}{c}\text { U de } \\
\text { Mann- } \\
\text { Whitney }\end{array}$ & $\begin{array}{c}\text { W de } \\
\text { Wilcoxon }\end{array}$ & $\mathbf{Z}$ & $\begin{array}{c}\text { Sig. } \\
\text { asintót. } \\
\text { (bilateral) }\end{array}$ \\
\hline Concentración total & 7 & 17 & $-1,529$ & 0,126 \\
Total arbóreas & 6 & 16 & $-1,698$ & 0,089 \\
Alnus & 0 & 10 & $-2,766$ & 0,006 \\
Betula & 6 & 16 & $-1,698$ & 0,089 \\
Populus & 4 & 14 & $-2,176$ & 0,03 \\
Prunus $\mathrm{t}$. & 8,5 & 18,5 & $-1,36$ & 0,174 \\
Quercus & 12 & 22 & $-0,679$ & 0,497 \\
Rhamnus & 16 & 52 & 0 & 1 \\
Salix & 16 & 52 & 0 & 1 \\
Tilia & 8,5 & 18,5 & $-1,285$ & 0,199 \\
Ulmus & 14 & 24 & $-0,707$ & 0,48 \\
\hline
\end{tabular}

Tab. 7. Trinchera minera de Gorny (TR) (Kargaly, región de Orenburgo, Rusia): resultados de la aplicación de la prueba del estadístico U de Mann-Whitney a la distribución de la variable "Total de Arbóreas" y los taxones mayoritarios (\% sobre la suma base) en las Fases 1 y 3 . 
camente equivalente en las fases pre-Srubnaya y post-Srubnaya, consideradas en conjunto.

El comportamiento de Betula y Salix, los otros taxones mayoritarios presentes en ambas fases, varía mucho. La cantidad de Salix permanece casi constante, mientras el aumento de Betula es significativo en la fase post-Srubnaya. Su valor es 2.41 veces mayor que en la pre-Srubnaya. Los resultados del test de Mann-Withney corroboran estas observaciones.

En resumen, el resultado de comparar las fases pre y post-Srubnaya en TR es bastante inesperado, habida cuenta de que el depósito está en el centro de un área de intensa actividad minera durante la fase Srubnaya, y fue el escenario de una ocupación permanente durante dicha fase. Según los niveles de concentración de polen de Quercus esta especie estaba muy presente en el entorno inmediato del depósito sin que la actividad minera, ni la ocupación humana directa supusieran un retroceso significativo en la cantidad de ejemplares. En cambio, el resto de los cambios observados entre las Fases 1 y 3 sí sugieren modificaciones en el paisaje en un radio algo más amplio. Destacan dos hechos: (1) el aumento de la diversidad de especies entre la Fase 1 y la 3 y (2) el significativo incremento de Betula. Tomados en conjunto sugieren una expansión de la cubierta forestal en el paisaje que rodea la colina Gorny. La identificación de Alnus en la Fase 3 indica la formación del bosque de ribera en la margen del río Usolka: las preferencias de esta especie descartan su presencia sobre la colina. Populus no puede usarse en apoyo de esa idea, ya que ignoramos si el polen fosilizado corresponde a Populus nigra, claramente ripario, o a $P$. tremula, cuya distribución actual es casi general en el territorio, aunque muestre una cierta vinculación con los cursos estacionales de agua. Otros taxones riparios, como Ulmus, Acer, Fraxinus y Sambucus, refuerzan la impresión de que durante la Fase 3 se establece una formación riparia, ausente o muy simplificada en la Fase 1. En efecto, la cantidad constante de polen de Salix, otro componente de la ripisilva fluvial que difícilmente pudo establecerse en el entorno árido de la colina Gorny, sugiere que, durante la Fase 1, el bosque de ribera del Usolka se reducía a los sauces de porte arbustivo que, aún hoy, forman su vegetación característica en los tramos donde falta la ripisilva. La recuperación de Betula puede tener dos lecturas: se debe a una colonización local de la colina Gorny, al estilo de la existente en la actualidad, ligada al abandono de las propias obras mineras, o bien es el resultado de la recuperación de los bosques galería en el barranco de Mijailovski, y, en general, en el paisaje del distrito Gorny.

Esta lectura implica la idea de que el polen de los taxones higrófilos procede de una cuenca de captación supralocal, que incluye un sector del río Usolka y parte del barranco de Mijailovski, en tanto que el de Quercus procede del entorno inmediato del depósito. Si se acepta esta hipótesis debe concluirse que la Fase 1 no representa un paisaje previo a la minería, sino uno minero consolidado, anterior a la ocupación Srubnaya de la colina. Ello concuerda con la formación del depósito en una estructura minera abandonada. Si el polen del depósito TR representa este escenario, cabe suponer, aunque nos falta un término de comparación ante quem, que la actividad minera durante la Fase 1 (entre 3350-2550 y 2300-1960 cal BC) había producido una pérdida sustancial de la masa forestal en los barrancos y en la ribera del Usolka.

En suma, los datos de TR nos permiten evaluar el impacto de las operaciones mineras de la Edad del Bronce en un sentido inverso al que se supondría en principio:

(1) la fase pre-Srubnaya no representa el paisaje natural previo al impacto de la minería prehistórica, sino un paisaje minero ya consolidado, definido por la ausencia, o extrema reducción de los elementos forestales.

(2) En la fase post-Srubnaya se refleja la restauración de los elementos de paisaje mencionados tras el fin del período.

La permanencia del roble en la propia colina Gorny durante toda la secuencia no contradice la intuición general sobre la excelencia de esta especie como combustible y material de construcción. Las prácticas de explotación sostenible no son desconocidas (Engel y Frey 1996: 38). Quizás los mineros de la Edad del Bronce reservaran una población de robles en la colina como combustible invernal, mediante una poda controlada. Lamentablemente, carecemos de bases para contrastar esta o cualquier otra hipótesis al respecto. La escasez de carbones de roble identificados en el poblado Gorny 1 (Uzquiano 2002) sorprende frente a la masiva presencia de polen de la especie en la trinchera. Su proporción se aproxima bastante a la distribución actual del roble en el distrito. Determinar si el aprovisionamiento de leña en el pa- 
sado reflejaba la dispersión de las especies en ese territorio requeriría otra investigación. Hay múltiples factores que definen las prácticas de recolección y tala de madera (Horne 1982b: 205-209; Engel y Frey 1996; Henry et al. 2009) y nuestra base empírica es insuficiente para evaluarlas.

\subsection{Análisis comparativo: datos paleopalinológicos y lluvia polínica reciente}

El análisis de la concentración de polen en TR y TUN ha definido los cambios en las cantidades absolutas de los taxones en cada depósito. Pero no permite compararlas entre si, ni con los de la lluvia polínica reciente. Tampoco podemos interpretar el contenido palinológico de las fases en términos de la morfología del paisaje forestal. Nos faltan datos fundamentales como la productividad y movilidad de polen de cada especie, entre otros. Las discontinuidades en los procesos de formación de los depósitos impiden incluir en el análisis muestras tan relevantes como las de la ocupación Srubnaya. La comparación de las frecuencias relativas de polen en cada muestra puede subsanar algunas de estas limitaciones. Perdemos la información cuantitativa directa sobre el volumen real de ejemplares emisores de polen e introducimos distorsiones dado que el porcentaje de cada taxón depende de los del resto. A cambio ganamos un marco de comparación generalizada sobre la composición proporcional por especies de las muestras que, bien manejado en conexión con un modelo del paisaje, nos aproxima a las tipologías de los entornos representados en las mismas, de acuerdo con el citado enfoque del "análogo óptimo actual" (BMA).

Se ensaya ahora esta estrategia a partir de un Análisis de Componentes Principales (ACP). La tabla de datos 8 incluye todas las muestras paleopalinológicas y de lluvia polínica reciente. Cada muestra está representada por el porcentaje con respecto a la suma base de todos los taxones que componen el grupo ecológico A, con las excepciones que se indicaron en la sección 3.1. Esta técnica explora la similitud estructural entre las muestras paleopalinológicas y sus potenciales análogos actuales.

El efecto de las variaciones en el balance arbóreas / herbáceas se incluye deliberadamente en la tabla por entender que el peso proporcional de

\begin{tabular}{|l|c|c|}
\hline & Inicial & Extracción \\
\hline Acer & 1,000 &, 658 \\
Alnus & 1,000 &, 611 \\
Betula & 1,000 &, 589 \\
Fraxinus & 1,000 &, 804 \\
Populus & 1,000 &, 704 \\
Prunus $t$. & 1,000 &, 841 \\
Quercus & 1,000 &, 844 \\
Rhamnus & 1,000 &, 621 \\
Rosaceae & 1,000 &, 825 \\
Salix & 1,000 &, 769 \\
Sambucus & 1,000 &, 802 \\
Ulmus & 1,000 &, 737 \\
Tilia & 1,000 &, 668 \\
\hline
\end{tabular}

Tab. 8. Análisis de Componentes Principales de las muestras paleopalinológicas y de la lluvia polínica reciente: comunalidades (Kargaly, región de Orenburgo, Rusia).

las arbóreas es un dato fundamental en la caracterización del perfil polínico de las muestras. El ACP reduce las 13 variables consideradas a 4 variables independientes que son combinaciones lineales de las originales. Cada componente principal (CP) es una variable teórica que da cuenta de una parte de la covarianza entre las variables iniciales e identifica un factor subyacente que explica la variabilidad concomitante de los datos. En este estudio estos factores subyacentes debieran ser de índole biogeográfica. Pero, al haber introducido en el problema las muestras paleopalinológicas, no sería prudente adelantar una interpretación biogeográfica de los factores cuando ignoramos hasta que punto los determinantes biogeográficos que definen el paisaje actual pueden ser extrapolados al pasado. Sólo podemos interpretar los resultados del experimento en términos clasificatorios. Asumimos que la distancia entre las muestras del grupo de control y las paleopalinológicas denota la analogía de las asociaciones de las especies leñosas en el conjunto de muestras analizado sin atribuirla un significado causal.

A partir de las ecuaciones que definen los CPs se calculan las "puntuaciones factoriales" para cada caso. Ello da lugar a una nueva tabla de datos en la que cada muestra queda definida en relación con los nuevos ejes de variabilidad. Un problema de ACP tiene numerosas soluciones, dado que cabe intentar mejorar la solución inicial mediante diversas técnicas matemáticas. Estas técnicas permiten modificar la posición de los ejes de 
combinación de las variables resultantes de la solución inicial, para aumentar la varianza explicada por el modelo, aumentar la independencia entre los CPs o clarificar la relación entre los CPs y el conjunto inicial de variables. Hemos optado por aplicar una "rotación Varimax" a partir de la solución original, porque la solución rotada es compatible con la inicial y con una interpretación basada en la "verdad terreno". Al comparar las tablas 10 A y B se puede observar que la segunda replica la estructura de la primera, pero con valores más próximos al límite de su tendencia $(1,-1$ o 0$)$. Los componentes extraídos explican un $72,875 \%$ de la varianza de los datos (Tab. 9). La solución rotada redistribuye esta varianza explicada entre los cuatro factores, de modo que su potencia explicativa queda más equilibrada que en la solución inicial.

\begin{tabular}{|c|c|c|c|c|c|c|c|c|c|}
\hline \multirow{2}{*}{$\begin{array}{c}\text { Compo- } \\
\text { nente }\end{array}$} & \multicolumn{3}{|c|}{ Autovalores iniciales } & \multicolumn{3}{|c|}{$\begin{array}{l}\text { Sumas de las saturaciones al } \\
\text { cuadrado de la extracción }\end{array}$} & \multicolumn{3}{|c|}{$\begin{array}{l}\text { Suma de las saturaciones al } \\
\text { cuadrado de la rotación }\end{array}$} \\
\hline & Total & $\begin{array}{c}\% \text { de la } \\
\text { varianza }\end{array}$ & $\begin{array}{c}\% \\
\text { acumu- } \\
\text { lado }\end{array}$ & Total & $\begin{array}{c}\% \text { de la } \\
\text { varianza }\end{array}$ & $\begin{array}{c}\% \\
\text { acumu- } \\
\text { lado }\end{array}$ & Total & $\begin{array}{c}\% \text { de la } \\
\text { varianza }\end{array}$ & $\begin{array}{c}\% \\
\text { acumu- } \\
\text { lado }\end{array}$ \\
\hline 1 & 4,910 & 37,773 & 37,773 & 4,910 & 37,773 & 37,773 & 3,177 & 24,439 & 24,439 \\
\hline 2 & 1,978 & 15,218 & 52,991 & 1,978 & 15,218 & 52,991 & 2,893 & 22,255 & 46,694 \\
\hline 3 & 1,380 & 10,616 & 63,606 & 1,380 & 10,616 & 63,606 & 1,959 & 15,070 & 61,764 \\
\hline 4 & 1,205 & 9,268 & 72,875 & 1,205 & 9,268 & 72,875 & 1,444 & 11,110 & 72,875 \\
\hline 5 &, 655 & 5,035 & 77,910 & & & & & & \\
\hline 6 &, 595 & 4,575 & 82,485 & & & & & & \\
\hline 7 &, 522 & 4,018 & 86,503 & & & & & & \\
\hline 8 & ,471 & 3,621 & 90,124 & & & & & & \\
\hline 9 & ,415 & 3,189 & 93,313 & & & & & & \\
\hline 10 & ,302 & 2,323 & 95,636 & & & & & & \\
\hline 11 & 244 & 1,874 & 97,510 & & & & & & \\
\hline 12 &, 180 & 1,386 & 98,896 & & & & & & \\
\hline 13 & 144 & 1,104 & 100,000 & & & & & & \\
\hline
\end{tabular}

Tab. 9. Análisis de Componentes Principales de las muestras paleopalinológicas y de la lluvia polínica reciente (Kargaly, región de Orenburgo, Rusia): varianza explicada por el modelo.

\begin{tabular}{|c|c|c|c|c|c|c|c|c|c|}
\hline \multirow{2}{*}{$\mathbf{A}$} & \multicolumn{4}{|c|}{ Componente } & \multirow{2}{*}{ B } & \multicolumn{4}{|c|}{ Componente } \\
\hline & 1 & 2 & 3 & 4 & & 1 & 2 & 3 & 4 \\
\hline Acer &, 548 &, 033 & ,270 &,- 533 & Acer & ,781 &,- 008 &, 182 &,- 123 \\
\hline Alnus & ,722 &,- 186 & ,197 &,- 128 & Alnus & ,701 &, 276 &,- 051 & ,203 \\
\hline Betula &, 735 & ,019 &,- 154 &, 155 & Betula & ,382 &, 643 &, 038 & , 167 \\
\hline Fraxinus & ,846 &,- 133 &, 134 &,- 231 & Fraxinus & ,812 & ,366 &,- 001 &, 104 \\
\hline Populus & 603 &, 002 &,- 583 &, 006 & Populus & ,212 &, 772 &,- 098 &,- 233 \\
\hline Prunus t. & ,085 &, 864 & ,295 &,- 016 & Prunus t. & ,005 &,- 023 & ,915 &, 055 \\
\hline Quercus & ,279 &,- 164 &, 530 & 677 & Quercus &, 060 &, 078 &,- 023 & ,913 \\
\hline Rhamnus & ,384 &, 490 &, 451 &, 175 & Rhamnus &, 249 & ,096 &, 617 & ,412 \\
\hline Rosaceae &,- 030 &, 870 &,- 179 &,- 185 & Rosaceae &,- 164 & ,142 & ,792 &,- 388 \\
\hline Salix &, 862 &,- 087 & ,095 &, 093 & Salix & ,622 &, 530 & ,018 & ,318 \\
\hline Sambucus &, 756 &, 275 &,- 359 &, 161 & Sambucus & 265 &, 824 &, 230 &, 010 \\
\hline Ulmus & ,739 &,- 241 &, 153 &,- 331 & Ulmus & 820 & ,231 &,- 104 &, 036 \\
\hline Tilia & ,612 & ,112 &,- 348 &, 400 & Tilia &, 068 &, 790 &, 051 & ,190 \\
\hline
\end{tabular}

Tab. 10. Análisis de Componentes Principales de las muestras paleopalinológicas y de la lluvia polínica reciente (Kargaly, región de Orenburgo, Rusia). A: matriz de componentes (solución inicial). B: matriz de componentes rotados. Método de rotación: Normalización Varimax con Kaiser. La rotación ha convergido en 6 iteraciones.

T. P., 67, N. ${ }^{\circ}$ 2, julio-diciembre 2010, pp. 511-544, ISSN: 0082-5638

doi: $10.3989 /$ tp.2010.10054 
La primera etapa del análisis consiste en interpretar el significado de los CPs a partir de la evaluación de la coherencia entre sus valores de correlación con las variables originales. Cada uno de los CPs describe una de las asociaciones básicas de especies arbóreas del paisaje de Kargaly. Cada CP presenta los valores más altos de correlación con grupos de taxones coherentes con esta hipótesis. A la vez, los taxones repetidos en varias asociaciones se correlacionan de modo significativo con varios CPs.

El componente 1 (CP-1) explica un 24,439\% de la varianza total de la tabla. Presenta los valores de correlación más altos $(>0,7)$ con el conjunto de taxones de la ripisilva: Acer, Alnus, Fraxinus y Ulmus. Es decir, CP-1 explica más del $50 \%$ de su varianza. Los valores del grupo son muy bajos o negativos en el resto de los CPs. Ello confirma que el significado de $\mathrm{CP}-1$ está vinculado a la formación forestal fluvial de la que son exclusivos. El valor algo inferior $(0,622)$ de Salix significa que no aparece sólo en esta formación. Lo atestigua su valor relativamente alto en CP-2. En Betula y Populus, con coeficientes < 0,5, esta tendencia se acentúa: sus valores son más altos en $\mathrm{CP}-2$ y sus correlaciones con CP-1 son a un nivel poco significativo. En Populus este efecto puede deberse a su ambivalencia taxonómica: P. nigra se asocia a la ripisilva fluvial y $P$. tremula a los bosques galería. Los valores de correlación del resto de taxones son casi nulos. En suma, el CP-1 representa el factor que determina la distribución de la ripisilva fluvial.

El componente 2 (CP-2) explica un 22,255\% de la varianza. Sus valores de correlación mayores de 0,5 son, por orden decreciente: Sambucus, Tilia, Populus, Betula y Salix. Este conjunto de taxones describe la asociación de los bosques galería de los barrancos.

El componente 3 (CP-3) explica un 15,070\% de la varianza total. Sólo presenta coeficientes $>$ 0,5 para Prunus t., Rosaceae y Rhamnus catharticus, taxones que caracterizan las formaciones arbustivas de las zonas áridas y, en especial, las mineras. El resto de los taxones muestran coeficientes muy bajos.

El componente 4 (CP-4) explica un 11,110\% de la varianza. Tiene una correlación muy fuerte con Quercus y valores poco significativos con los demás taxones, salvo Rhamnus y, en menor medida, Salix. Pensemos que las correlaciones con $\mathrm{Po}_{0}$ pulus y el grupo Rosaceae son negativas. Cabe decir que la proporción de polen de roble es por si misma un factor independiente del comportamiento del resto de los grupos de taxones.

En conclusión, los cuatro componentes "miden" el peso de grupos de taxones sintetizados por los componentes que describen la tipología de formaciones forestales existentes en el área de estudio. La representación de los casos (las muestras individuales), en el espacio de cuatro dimensiones definido por los CPs, fija el grado de analogía de las muestras paleopalinológicas con las de la lluvia polínica actual respecto a los ejes de variabilidad definidos por dichas dimensiones. Esta analogía puede interpretarse, hasta cierto punto y con las precauciones avanzadas, en términos fitosociológicos, dado que las proporciones de polen dependen de la distribución efectiva de la vegetación. Cabe usar, entonces, las muestras de la lluvia polínica reciente, cuyos entornos conocemos, para aproximar el tipo de entorno representado por las muestras antiguas. Es enorme la cantidad de información que puede obtenerse de un enfoque de este tipo, en especial si se combina con el uso analítico de un modelo del paisaje. Como su desarrollo excede los límites de este trabajo, nos limitaremos a señalar algunos aspectos relevantes de las conclusiones obtenidas al analizar las secuencias paleopalinológicas.

Las figuras 10 y $11 \mathrm{~A}$ muestran la distribución de las muestras de cada serie paleopalinológica junto con las del grupo de control en los espacios bidimensionales definidos por las combinaciones bivariables del CP-1 con el resto. Los mapas de la figura 12 representan la distribución espacial de los valores de las muestras de la fase reciente (incluyendo las superficiales de TR y TUN) en cada uno de los CP.

El primer comentario es que, considerando la totalidad de las combinaciones bivariables de los CPs, ninguna muestra del grupo de control puede verse como un análogo absoluto de los conjuntos paleopalinológicos. Sí hay análogos parciales en alguna de las combinaciones y en relación con CPs aislados. La serie TUN siempre se diferencia claramente del grupo de control y de TR, aunque los valores de algunas muestras recientes son similares para CP-1, CP-2 y CP-3. En especial es significativa la posición de TUN en la figura 10A (relación entre la composición de las dos principales formaciones riparias). La mayoría de las muestras del grupo de control se agrupan en torno al valor 0 de los dos componentes, como corres- 


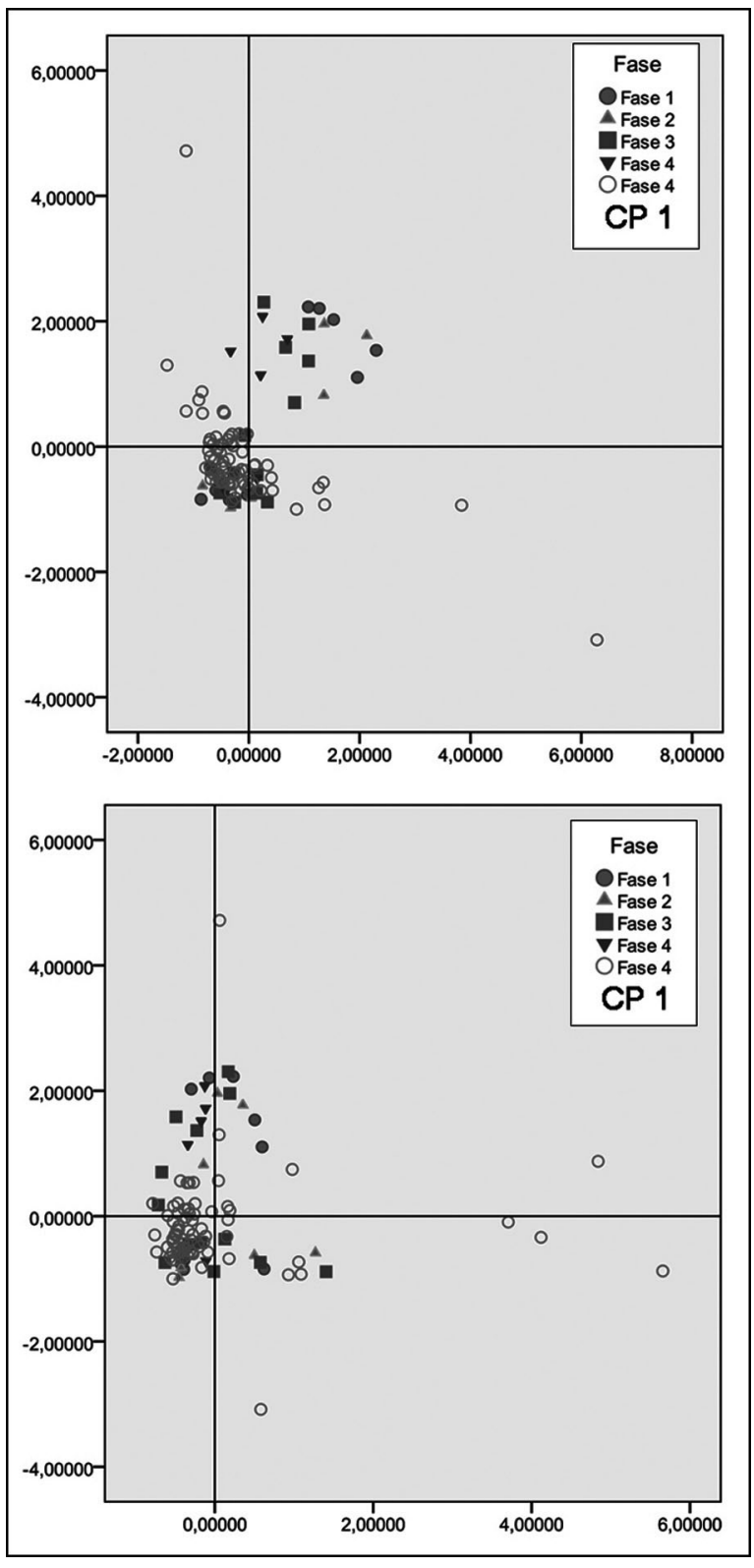

Fig. 10. Análisis de Componentes Principales en las muestras de cada serie paleopalinológica y del grupo de control (Kargaly, región de Orenburgo, Rusia). A: Puntuaciones factoriales, Componentes 1 (ordenadas) y 2 (abscisas). B: Puntuaciones factoriales, Componentes 1 (ordenadas) y 4 (abscisas).

ponde a que la mayoría tienen valores muy bajos de arbóreas. Las muestras tomadas dentro de formaciones forestales se ven muy bien: las asociadas al bosque ripario fluvial en el cuadrante superior izquierdo y las relacionadas con bosques galería de barrancos en el inferior derecho

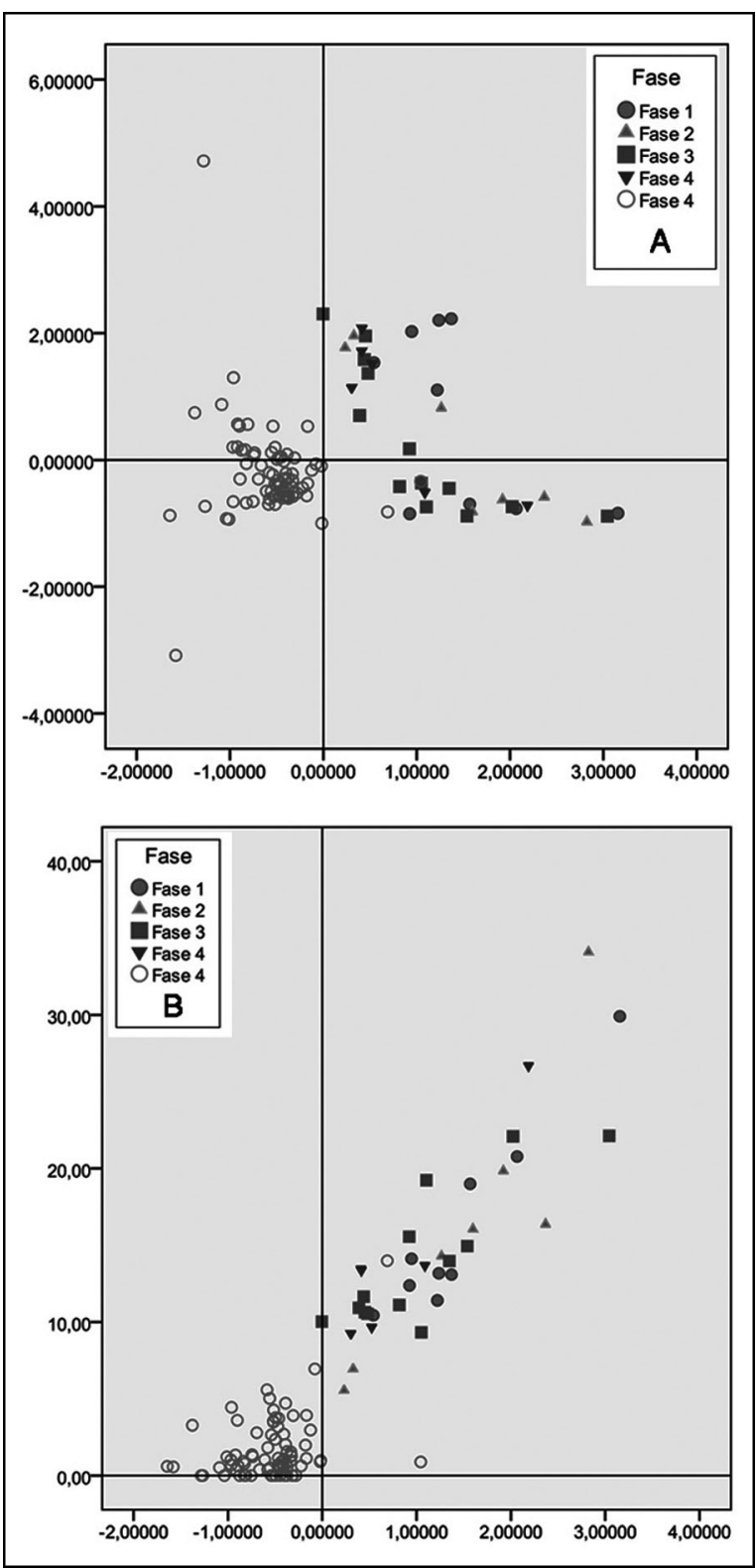

Fig. 11. Análisis de Componentes Principales. A: Puntuaciones factoriales, Componentes 1 (ordenadas) y 4 (abscisas) en las muestras de cada serie paleopalinológica y del grupo de control (Kargaly, región de Orenburgo, Rusia). B: Correlación entre el porcentaje de Quercus (ordenadas) y el Componente Principal 4 (CP4) (abscisas).

(Fig. 12: CP1 y CP2 respectivamente). La mayoría de las muestras de TUN están en el cuadrante superior derecho. Ello significa que tiene valores elevados en todos los taxones de ambos grupos. Tal combinación no aparece en ninguna muestra reciente y podría describirse como un bosque flu- 
vial (formado por Alnus, Ulmus, Acer, Salix y posiblemente Populus nigra) con una cantidad de Betula típica de los bosques galería actuales.

En la misma figura 10A, todas las muestras de TR se agrupan con el grueso de las muestras de control en torno al valor 0 de ambos ejes. Es decir, las muestras de TR son indistinguibles del perfil dominante de las recientes en el peso de los taxones riparios. Su perfil es "estepario", con niveles muy bajos de todas las arbóreas citadas hasta ahora.

La segregación de las muestras de TUN, respecto al grupo de control, desaparece y la integración de TR se mantiene, en la figura 10B, en la que interviene el CP-3. Esto muestra el bajo nivel de representación de los taxones asociados con las áreas mineras (Fig. 12: CP3). Son varias las interpretaciones del ligero desplazamiento de algunas muestras paleopalinológicas sobre el eje del CP-3. El serbal (Sorbus aucuparia), reconocido en algunos bosques galería, puede quedar re- gistrado en el grupo Rosaceae. Ello explicaría el valor significativo del grupo en algunas muestras de TUN. También algunas muestras de TR pueden estar influidas por las áreas mineras próximas. Ello confirmaría la existencia en la fase más antigua de un paisaje minero consolidado. Por desgracia no tenemos datos suficientes para decir sobre estas hipótesis.

El CP-4 discrimina bien el conjunto de las muestras paleopalinológicas de ambas series del grupo de control (Fig. 11A). Por ello, la interpretación del significado biogeográfico de este componente es de gran importancia. Sólo MO_7 y MA_23 del grupo de control presentan un valor positivo para este CP y por razones distintas. MO_7, obtenida en el interior del único relicto de Quercus en el área de estudio, contiene un $13,99 \%$ de polen de este taxón. En MA_23, la proporción de polen de Quercus es baja $(0, \overline{8} 8 \%)$. Su elevado valor para el CP-4 se debe a ser el máximo absoluto en toda la tabla de Rhamnus cat-
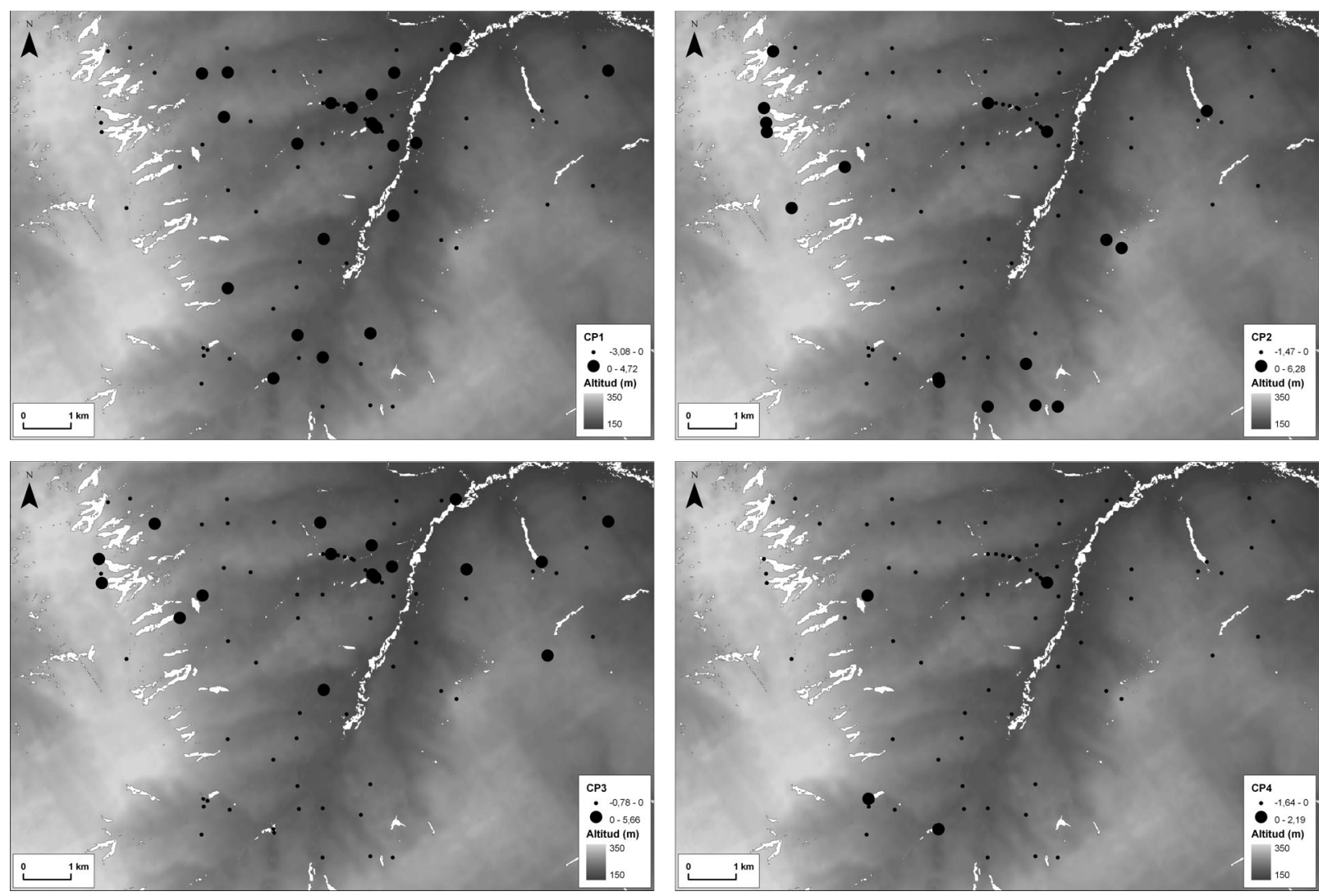

Fig. 12. Distribución espacial de los valores de las puntuaciones factoriales de las muestras palinológicas de la fase reciente (incluyendo las superficiales de la Trinchera minera de Gorny y la Turbera de Novenki) en cada uno de los Componentes Principales (CP) (Kargaly, región de Orenburgo, Rusia). 
harticus, el espino cerval (2,65\%), además de tener cantidades importantes de Prunus t. y Rosaceae. La muestra procede de las proximidades de una zona minera. En la figura 11A es la única muestra reciente a la derecha del eje de ordenadas, aunque muy separada de las muestras paleopalinológicas. En cambio MO_7, incluida en la nube de puntos formada por éstas, sí constituye un análogo de las muestras antiguas.

La proporción de polen de Quercus explica el $83 \%$ de la varianza de CP-4, con el que guarda una alta correlación lineal (Fig. 11B). Puede decirse que este taxón distingue decisivamente las muestras del grupo de control de las paleopalinológicas. En cuanto a la interpretación de este hecho en términos biogeográficos, pensamos que la especie debió estar más generalizada en el pasado, dado que hoy se reduce a un pequeño relicto en el distrito de Novenki (Fig. 12: CP2). En la colina Gorny, el análisis de la secuencia estableció que hubo una población local de robles hasta la fase reciente. En TUN, en cambio, parece más plausible atribuir las altas concentraciones de Quercus a la dispersión a más larga distancia, lo que no contradice que formara parte del paisaje del distrito de Novenki en mayor medida que en la actualidad.

Como se ve en la figura 12: CP4, la distribución actual del polen de Quercus no puede explicarse sólo por la dispersión a partir del relicto de Novenki. La desaparición del roble en la región se produce durante la fase reciente debido al amplio impacto de la minería rusa, la agricultura soviética o la acción acumulada de ambas. Este hecho trascendental determina que, salvo una excepción, no haya muestras del grupo de control asociadas con claridad a las paleopalinológicas en los cuatro CPs. Es decir, el paisaje actual no proporciona ningún análogo óptimo para las fases de las dos secuencias analizadas, aunque sí análogos parciales, como MO_7.

En conclusión, el análisis comparativo exploratorio de las similitudes entre las series paleopalinológicas y el grupo de control no ha localizado análogos óptimos en el paisaje actual. Las diferencias entre las muestras antiguas y recientes permiten identificar un elemento del paisaje forestal, el roble, cuyo peso notable en el pasado no se constata en la actualidad.

Un examen más detallado de los resultados del ACP podría matizar las analogías parciales reconocibles.

\subsection{Polen y carbones}

Como se indicó, los datos paleopalinológicos se contrastaron con muestras de carbón de hogares domésticos y fuegos metalúrgicos. Se obtuvieron en las tres fases de ocupación del poblado Gorny 1 durante la excavación de 1994. Los datos antracológicos son insuficientes para sacar conclusiones cuantitativas. No obstante la información que aportan es muy importante para la discusión de los recursos energéticos. La muestra identifica de modo directo las especies leñosas usadas durante la Edad del Bronce, en tareas de subsistencia y metalúrgicas. Su contenido representa las pautas de aprovisionamiento asociadas con ellas y, por lo tanto, está sesgado por preferencias que dependen de factores económicos $\mathrm{y}$ culturales, y no sólo de la disponibilidad de dichas especies. Por ello, estos datos no son útiles como fuente de información directa sobre la distribución de los recursos forestales. En cambio, la comparación entre el inventario antracológico y las distribuciones de polen de las fases de la Edad del Bronce de la serie TR ilustra sobre las propias pautas de explotación energética de dichos recursos, ofreciendo una perspectiva sobre los mecanismos de la acción antrópica sobre el paisaje. Esta comparación puede aclarar otros aspectos relevantes del propio registro palinológico, como la distorsión causada por la sobrerrepresentación de la vegetación local del punto de muestreo.

La tabla 11 A presenta el total de muestras identificadas, en las tres fases de ocupación de Gorny 1 (Uzquiano 2002). La tabla 11 B recoge el porcentaje promedio de cada taxón para cada fase de TR, calculado con respecto a la suma de los taxones incluidos en el inventario antracológico. Todas las alusiones a datos palinológicos en esta sección se referirán a esta suma base.

Sólo 7 de las 14 clases de palinomorfos identificadas dentro del grupo A, fueron utilizadas como combustible. El grado de precisión taxonómica de las identificaciones antracológicas plantea algunos problemas para la comparación. El género Populus se distribuye en el grupo antracológico Populus tremula y en el Populus / Salix. Ninguno de los dos tiene un equivalente palinológico ya que, como sabemos, las dos especies locales de Populus están agregadas en el inventario palinológico. Es decir, no se pueden comparar directamente las dos series de datos relativas a $\mathrm{Po}$ pulus y Salix. 


\begin{tabular}{|l|r|r|l|r|r|r|r|}
\hline \multicolumn{1}{|c|}{ A } & Muestras & \% & \multicolumn{1}{c|}{ B } & TR_1 & TR_2 & TR_3 & TR_4 \\
\hline Betula pendula & 176,00 & 34,65 & Betula & 13,88 & 11,21 & 16,27 & 16,09 \\
Populus tremula & 134,00 & 26,38 & Populus & 0,00 & 0,89 & 6,05 & 7,21 \\
Populus-Salix & 105,00 & 20,67 & Salix & 5,42 & 6,59 & 4,69 & 8,58 \\
Alnus incana & 84,00 & 16,54 & Alnus & 0,00 & 1,85 & 6,70 & 3,15 \\
Quercus & 5,00 & 0,98 & Quercus & 78,90 & 73,20 & 60,68 & 61,61 \\
Rhamnus t. catharticus & 3,00 & 0,60 & Rhamnus t. & 0,90 & 1,45 & 1,16 & 0,00 \\
Prunus sp. & 1,00 & 0,20 & Prunus t. & 0,90 & 4,80 & 4,45 & 3,36 \\
TOTAL & 508.00 & & Betula & 13,88 & 11,21 & 16,27 & 16,09 \\
\hline
\end{tabular}

Tab. 11. A: Muestras antracológicas identificadas, en las tres fases de ocupación del poblado Gorny (Uzquiano 2002). B: Porcentaje promedio de cada taxón para cada fase de la Trinchera minera (TR), respecto a la suma de los taxones incluidos en el inventario antracológico (Kargaly, región de Orenburgo, Rusia).

El resto de los taxones han sido identificados a nivel de especie y corresponden a todas las asociaciones definidas: la ripisilva fluvial (Alnus, $\mathrm{Sa}$ lix y, posiblemente Populus nigra), los bosques galería (Betula, P. tremula) y el matorral espinoso (Rhamnus, Prunus t.). La proporción de Quercus es llamativamente inferior a su peso en el registro palinológico de la Fase 2 lo que se valorará más abajo. La ausencia de Ulmus, Fraxinus y Acer, confirma los datos palinológicos de las Fases 1 y 2 de TR.

La presencia de todas las formaciones y la inclusión de elementos de desigual calidad como combustible sin una preferencia clara por los más eficientes (Quercus) sugiere unas prácticas de aprovisionamiento oportunistas y poco selectivas, desarrolladas sobre un territorio que incluía la ripisilva fluvial y los bosques galería de los barrancos. Por desgracia, la agregación Populus / Salix impide calcular el peso proporcional de cada dominio ecológico en el conjunto.

La estructura general de las dos series tiene analogías: Betula es el taxón más probable, si no tenemos en cuenta Quercus; el valor palinológico de Salix se aproxima al del agregado antracológico Populus / Salix; Alnus incana es el taxón de la ripisilva fluvial más destacado tras Salix; los valores de Rhamnus y Prunus t. son muy marginales. Estas analogías permiten resaltar el valor de las discrepancias que afectan a Populus tremula y Quercus.

Populus tremula representa, como mínimo, el $26,38 \%$ de los carbones identificados. Por su parte, la suma de todos los palinomorfos del género Populus en la Fase 2 promedia el $0,89 \%$ con respecto a la suma de los taxones representados en el inventario antracológico. Teniendo en cuenta que este taxón está ausente en la Fase 1 y pasa a tener valores de $6,05 \%$ en la Fase 3 y $7,21 \%$ en la Fase 4, podemos concluir que sus numerosos carbones en la Fase 2 sólo pueden explicarse asumiendo el aprovisionamiento de leña sobre un territorio cuyo radio excedía al de la cuenca de captación de polen. No es posible reconstruir positivamente estas dimensiones, pero resulta ilustrativo que Populus sólo falte en 3 de las 76 muestras de lluvia polínica reciente, y que su promedio en esta serie sea el $26,77 \%$. De ello podemos deducir que la productividad y capacidad de dispersión del polen de las especies incluidas en este género son relativamente elevadas. Si esto es así, cabría suponer que conseguir madera de Populus requirió un desplazamiento considerable para los habitantes del poblado Gorny 1.

La situación de Quercus es exactamente inversa. Destacan sus elevados valores en el registro palinológico $(73,20 \%$ del total del inventario) frente a su escasez en la muestra antracológica ( $1 \%$ de los restos identificados). El primer valor se aproxima bastante al de la muestra MO_7 (71\%) obtenida en el interior del relicto de robles. Ello refuerza la asunción previa de que en el entorno inmediato de la trinchera minera de Gorny hubo ejemplares de roble durante la Edad del Bronce. La escasez de carbones de roble plantea que o bien la especie se desestimó intencionalmente como combustible o bien su representación en el registro palinológico no corresponde a su disponibilidad efectiva cuando funcionaba el poblado. La primera opción no parece razonable, puesto que la madera de roble tiene unas características idóneas para ese uso. Descartamos la segunda con referencia al entorno inmediato del punto de muestreo, máxime valorando la continuidad a niveles parecidos en la sobrerrepresentación del roble durante todas las fases. Para sol- 
ventar esta paradoja aparente se puede aplicar el mismo argumento que en el caso de Populus. La proporción de Quercus en la serie antracológica no corresponde a su disponibilidad en el área de captación de polen de TR, sino en el conjunto del territorio sobre el que los habitantes del poblado se abastecían de madera. De ser correcto este razonamiento debemos concluir que el roble era muy escaso en el distrito minero de Gorny, a excepción de en la propia colina, lo cual matiza las conclusiones obtenidas en la sección anterior.

En suma, los datos antracológicos nos acercan a las pautas de aprovechamiento de recursos forestales y su disponibilidad en el entorno del poblado Gorny 1. Las conclusiones corroboran las obtenidas en el análisis palinológico de la secuencia TR: el entorno de Gorny estaba muy deforestado ya desde la Fase 1. Ello determinó un aprovisionamiento de combustible en un territorio extenso y según pautas poco selectivas.

La comparación entre las series de carbón y polen confirma, por otra parte, el peso de los factores locales en la representación palinológica de la distribución de la vegetación y la dificultad de establecer generalizaciones basadas en el análisis de series aisladas de datos.

\section{CONCLUSIONES}

El presente trabajo tiene un carácter experimental, y por lo tanto las conclusiones que cabe extraer de él en el plano de la historia de los recursos forestales de Kargaly son forzosamente provisionales en tanto no se realice un análisis que incluya todos los grupos ecológicos del inventario palinológico. No obstante el realizado, con todas las limitaciones que se han ido señalando, pone de manifiesto hechos empíricos que, independientemente de su interpretación, pueden considerarse evidencias sustantivas a tener en cuenta en las ulteriores investigaciones. Algunos de estos resultados ponen en cuestión las hipótesis de trabajo que habíamos mantenido al plantear el trabajo. Por eso, y al margen de ellos, consideramos posible extraer algunas conclusiones de orden metodológico en el campo de la aplicación de las disciplinas paleoambientales a la Arqueología del Paisaje. En esta recapitulación final enumeraremos brevemente estos dos grupos de conclusiones.
Desde el punto de vista histórico lo más importante es haber distinguido claramente dos trayectorias diferentes en la historia del paisaje de Kargaly. La primera está en relación directa con las obras minero-metalúrgicas en el área de Gorny. La segunda se conecta con las actividades pastoriles en la zona de Novenki. En ambas los resultados son consecuencia de la comparación entre las fases más antiguas ( 1 y 2) y la posterior al final de la Edad del Bronce (3), y modifican sustancialmente las hipótesis de trabajo.

Lo más inesperado ha sido constatar el grado de deforestación de la primera de las áreas en la fase más antigua. Esto significa que la actividad minera tuvo una escala apreciable desde el comienzo de la Edad del Bronce (fase Yamnaya) en el IV milenio cal BC, y que esta escala se mantuvo durante el Bronce Medio y Final, ya en el II milenio cal BC. De esta forma, el impacto antrópico de la fase de máxima intensidad minera, durante el Bronce Final (fase Srubnaya) no se constata por la pérdida de cubierta forestal entre las Fases 1 y 2, sino por la expansión de la misma durante la Fase 3.

Por el contrario, el área de Novenki presenta una trayectoria inversa: un máximo de cobertura forestal durante la Fase 1, seguida de un brusco descenso coincidiendo con la ocupación del poblado Novenki durante la Fase 2, y un sostenido declive hasta la actualidad. Dada la ausencia de minería en el área, y sus características biogeográficas, esta trayectoria puede ponerse en relación con el uso continuo de la misma como pastizal desde el II milenio cal BC hasta el presente.

El propio hecho de que las trayectorias de dos emplazamientos tan cercanos sean inversas apoya la idea de que los cambios observables no deben ser atribuidos en primer término a alteraciones climáticas.

Un resultado especialmente significativo es la identificación de una cantidad importante de robles en el paisaje regional durante toda la secuencia, con carácter local en Gorny y supralocal en Novenki. El dato de que las muestras de lluvia polínica reciente conserven una significativa representación de este taxón, inexplicable a partir del único relicto localizado, indica que su extinción es muy moderna y posiblemente se explica por el impacto de la minería de época moderna y/o la colonización agrícola posterior. Debe señalarse que el peso de Quercus no se puede establecer por su abundancia relativa en la secuencia 
TR, sino por su elevada proporción en TUN, un emplazamiento en el que es improbable una implantación local por razones biogeográficas. En cualquier caso, la posible existencia de Quercus debe tenerse en cuenta en la evaluación de las bases energéticas de la metalurgia de Kargaly.

Este resultado nos conduce a una importante conclusión metodológica: el dispositivo de comparación controlada que se ha establecido en el diseño de la investigación distingue los componentes local y supralocal de la variabilidad representada en los espectros polínicos. Generalizando este resultado tenemos que no cabría tal discriminación analizando una sola secuencia, incluso si el análisis incluyera varias secuencias paleopalinológicas pero careciera del apoyo de datos sobre la variabilidad de la lluvia polínica reciente apoyados por un modelo analítico del paisaje actual y datos arqueológicos complementarios, como en este caso han sido los antracológicos. Por otra parte, un enfoque comparativo complejo, como el que se propone aquí, sólo es viable aplicando modelos estadísticos. La modelización probabilística de las hipótesis y los datos permite establecer criterios de certeza en la comparación. La estadística palinológica es un campo abierto y de extraordinaria complejidad. Las alternativas que hemos adoptado requerirán de un desarrollo crítico en el futuro. En cualquier caso, esperamos haber contribuido a demostrar su viabilidad y fecundidad.

Para terminar, hay que subrayar que el tratamiento arqueológico de las muestras paleopalinológicas, prestando especial atención a los procesos de formación de los depósitos y al apoyo de cronologías absolutas, es un elemento fundamental en un enfoque histórico y paisajístico de la palinología arqueológica.

\section{AGRADECIMIENTOS}

A Salvador Rovira Llorens, a quien dedicamos esta contribución como homenaje personal y en reconocimiento a todo lo que nuestra investigación debe a la suya.

A E.N. Chernyj, E.E. Antipina, L.I. Avilova, T.B. Bartseba, S.A. Bykov, A.A. Karpujin, S.V. Kuzminyj, E.Yu. Lebedeva, V.Yu. Lunkov, L.B. Orlovskaia y D.V. Valkov (Laboratorio de métodos científico-naturales, Instituto de Arqueología, Academia Rusa de Ciencias, Moscú) gracias a cuyo apoyo científico y personal hemos formado parte del proyecto Kargaly. Muy especialmente recordamos la ayuda permanente de Tamara O. Teneishvili y los riesgos que con tanta generosidad asumió para hacerla efectiva. Pilar López García (CSIC), Ángel Rodríguez Alcalde (CSIC) y Paloma Uzquiano (UNED) participaron en el arranque de la investigación.

La dirección del Instituto de Arqueología de Moscú y la Subdirección, mas tarde Vicepresidencia, de Relaciones Internacionales del CSIC apoyaron la política de intercambio científico. El Excmo. y Mgfco. Rector de la Universidad Politécnica de Madrid, D. S. de la Plaza Pérez autorizó la participación de I. de Zavala Morencos en el proyecto.

A Héctor D'Antoni, inspirador del programa combinado de teledetección espacial y palinología, por compartir con nosotros su amplia concepción de los estudios paleoambientales.

A Isabel del Bosque González y Carlos Fernández Freire (Unidad de Sistemas de Información Geográfica, CCHS-CSIC, Madrid) por su contribución a la realización final del programa de teledetección espacial.

A Antonio Uriarte González (Laboratorio de I+D de Arqueología: Laboratorio de arqueología del paisaje y teledetección, CCHS-CSIC, Madrid) por su apoyo constante en muchas de las fases del trabajo y, muy especialmente, por sus decisivas sugerencias sobre el análisis estadístico.

A Enrique Capdevila Montes por su ayuda en la preparación de la documentación gráfica.

\section{BIBLIOGRAFÍA}

Agapov, S.A.; Kuzminyj, S.V. y Terejin, S.A. 1989: "Modelirovanie protsessov drevnei plavki medi". En E.N. Chernyj (ed.). Estestvennonauchnye metody Arjeologii. Sbornik nauchnyx trudov. Nauka. Moskva: 100-108.

Bennett, K.D. y Hicks, S. 2005: "Numerical analysis of surface and fossil pollen spectra from northern Fennoscandia". Journal of Biogeography 32: 407-423.

Breitenlechner, E.; Hilber, M.; Lutz, J.; Kathrein, Y.; Unterkircher, A. y Oeggl, K. 2010: "The impact of mining activities on the environment reflected by pollen, charcoal and geochemical analyses". Journal of Archaeological Science 37, 7: 1458-1467.

Broström, A.; Gaillard, M.J.; Ihse, M. y Odgaard, B. 1998: "Pollen-landscape relationships in modern analogues of ancient cultural landscapes in southern Sweden - a first step towards quantification of 
vegetation openness in the past". Vegetation History and Archaeobotany 7: 189-201.

Broström, A.; Sugita, S.; Gaillard, M.J. y Pilesjö, P. 2005: "Estimating the spatial scale of pollen dispersal in the cultural landscape of southern Sweden". The Holocene 15: 252-262.

Chernyj, E.N. 2002a: "Drevneishie vypabotki na jolme Gornogo". En E.N. Chernyj (ed.): Kargaly II. Yazyki Slavianskoi kultury. Moskva: 128-139.

Chernyj, E.N. 2002b: "Poselok Gornyi: pozdni bronzovyi vek". En E.N. Chernyj (ed.): Kargaly II. Yazyki Slavianskoi kultury. Moskva: 12-25.

Chernyj, E.N. 2002c: “"Russki' dom na poselenii brozobogo veka u Gornogo". Kargaly I. Yazyki Slavianskoi kultury. Moskva: 94-102.

Chernyj, E.N. 2002d: "Absoliuotnaia jronologiia pozdnebronzovyj sloev Gornovo". En E.N. Chernyj (ed.): Kargaly II. Yazyki Slavianskoi kultury. Moskva: 125-127.

Chernyj, E.N. 2004: Kargaly III Yazyki Slavianskoi kultury. Moskva.

Chernyj, E.N. 2005: Kargaly IV. Yazyki Slavianskoi kultury. Moskva.

Chernyj, E.N. 2007: Kargaly V. Yazyki Slavianskoi kultury. Moskva.

Chernyj, E.N.; Kuzminyj, S.V. y Lunkov, V.Yu. 2002: "Arjeologicheskie pamiatniki Kargalov". En E.N. Chernyj (ed.): Kargaly I. Yazyki Slavianskoi kultury. Moskva: 56-75.

Chernyj, E.N. y [Martínez] Navarrete, M.I. 2004: "Novye radioyglerodnye daty dlia karera rannebronzobogo bremeni". En E.N. Chernyj (ed.): Kargaly III. Yazyki Slavianskoi kultury. Moskva: 295-297.

Chernyj, E.N. y Martínez Navarrete, M.'I. 2005: "Raspredelenie radiouglerodnyj dat $\mathrm{v}$ kulturnom sloe $\mathrm{i}$ za ego predelami (poselenie Gornyi, Kargaly)". En E.N. Chernyj y V.N. Zavialov (eds.): Arjeologiia estestvennonauchnye metody. Yazyki Slavianskoi kultury. Moskva: 58-71.

Chernykh, E.N. 1992: Ancient Metallurgy in the USSR. The Early Metal Age. Cambridge University Press. Cambridge.

Chernykh, E.N. 1994: 'L'ancienne production minière et métallurgique et les catastrophes écologiques anthropogènes: introduction au problème". Trabajos de Prehistoria 51(2): 55-68.

Chernykh, E.; Frère-Sautot, M.-Ch.; Happ, J. y Rovira, S. 1999: "Experimentations de fonderie dans le site de minerai de cuivre de Kargali (Oural-Russie)". CU+. Bulletin du Groupe de Travail International sur la paléométallurgie des cuivres et des minerais associés. Association pour la Promotion de l'Archéologie de Bourgogne (A.P.A.B.) 1: 2-4.

Chibiliov, A.A. 1999: "Rastitelnost. Lesnye pamiaktniki”. En A.A. Chibiliov (ed.): Geograficheski
Atlas Orenburskoi Oblasti. Orenburgskoe knizhnoe izdatelstvo. Moskva: 50-51.

D’Antoni, H. y Spanner, M.A. 1993: "Remote sensing and modern pollen dispersal in Southern Patagonia and Tierra Del Fuego (Argentina): Models for Palaeoecology". Grana (32): 29-39.

Díaz-del-Río, P.; López García, P.; López Sáez, J.A.; Martínez Navarrete, M. ${ }^{a}$ I.; Rodríguez Alcalde, A.L.; Rovira Llorens, S.; Vicent García, J.M. \& Zavala Morencos, I. de. 2006: "Understanding the productive economy during the Bronze Age through archaeometallurgical and palaeoenvironmental research at Kargaly (Southern Urals, Orenburg, Russia)". En D.L. Peterson, L.M. Popova y A.T. Smith (eds.): Beyond the Steppe and the Sown: Proceedings of the 2002 University of Chicago Conference on Eurasian Archaeology. Colloquia Pontica 13. Brill. Leiden, Boston, 2006: 343-357. http://hdl.handle.net/10261/9727 (acceso 19-11-2010).

Engel, Th. y Frey, W. 1996: "Fuel resources for copper smelting in antiquity in selected woodlands in the Edom highlands to the Wadi Arabah/ Jordan". Flora 191: 29-39.

Gavin, D.G.; Oswald, W.W.; Wahl, E.R. y Williams, J.E. 2003: "A statistical approach to evaluating distance metrics and analog assignments for pollen records". Quaternary Research 60: 356-367.

Grattan, J.P.; Gilbertson, D.D. y Hunt, C.O. 2007: "The local and global dimensions of metalliferous pollution derived from a reconstruction of an eight thousand year record of copper smelting and mining at a desert-mountain frontier in southern Jordan". Journal of Archaeological Science 34: 83-110.

Guiot, J. 1990: "Methodology of the last climatic cycle reconstruction from pollen data". Palaeogeography, Palaeoclimatology, Palaeoecology 80: 49-69.

Healy, J.F. 1978: Mining and metallurgy in the Greek and Roman world. Thames and Hudson. London.

Henry, A.; Théry-Parisot, I. y Voronkova, E. 2009: "La gestion du bois de feu en forét boréale: archéo-anthracologie et ethnographie (région de l'Amour, Sibérie)". En I. Théry-Parisot, S. Costamagno y A. Henry (ed.): Gestion des combustibles au paléolithique et au mésolithique. Nouveaux outils, nouvelles interprétations. Actes du XV Congrès Mondial (Lisbonne, 2006). British Archaeological Reports, International Series 1914, Archaeopress. Oxford: 17-37.

Hicks, S. y Birks, H.J.B. 1996: "Numerical analysis of modern and fossil pollen spectra as a tool for elucidating the nature of fine-scale human activities in boreal areas". Vegetation History and Archaeobotany 5: 257-272. 
Horne, L. 1982a: "Fuel for the metal worker. The Role of Charcoal and Charcoal Production in Ancient Metallurgy". Expedition 25(1): 6-13.

Horne, L. 1982b: “The Demand for Fuel: Ecological Implications of Socio-Economic Change". En B. Spooner y H.S. Mann (eds): Desertification and Development: Dryland Ecology in Social Perspective. Academic Press Inc. London: 201-215.

Jouffroy-Bapicot, I.; Pulido, M.; Baron, S.; Galop, D.; Monna, F.; Lavoie, M.; Ploquin, A.; Petit, Ch.; Beaulieu, J-L. de y Richard, H. 2007: "Environmental impact of early palaeometallurgy: pollen and geochemical analysis". Vegetation History and Archaeobotany 16: 251-258.

Knapp, A.B. 1998: "Social Approaches to the archaeology and anthropology of mining". En A. Bernard Knapp, Vincent C. Pigott y Eugenia W. Herbert (eds.): Social Approaches to an Industrial Past. The Archaeology and Anthropology of Mining. Routledge. London, New York: 1-23.

Kohl, Ph.L. 2007: The Making of Bronze Age Eurasia. Cambridge University Press. Cambridge.

Korobov, D.S. 2004: "Predislovie". Kruglyi stol "Geoinformatsionnye tejnologi v arjeoligischeskij issledovaniiaj" (Moskva, 2003): Sb. Dokl. AGIS, Institut Arjeologii RAN. Moskva, CD-ROM.

Kremenetski, C.V.; Bittger, T.; Junge, F.W. y Tarasov, A.G. 1999: "Late- and postglacial environment of the Buzuluk area, middle Volga region, Russia". Quaternary Science Reviews 18: 1185-1203.

Kristiansen, K. 2007: "Eurasian Transformations: Mobility, Ecological Change, and the transmisión of Social Institutions in the Third Millennium and the Early Second Millennium b.c.e.”. En A. Hornborg y C.L. Crumley (eds.): The world system and the Earth system: global socio-environmental change and sustainability since the Neolithic. Left Coast Press. Walnut Creek, CA: 149-162.

Kristiansen, K. y Larsson, T.B. 2005: The rise of Bronze Age society. Travels, Transmissions and Transformations. Cambridge University Press. Cambridge.

López, P.; López-Sáez, J.A.; Chernykh, E.N. y Tarasov, P. 2003: "Late Holocene vegetation history and human activity shown by pollen analysis of Novienki peat bog (Kargaly region, Orenburg Oblast, Russia)". Vegetation History \& Archaeobotany 12: 75-82.

López-Sáez, J.A. 2002: “Glossari: sovremennaia flora Kargalov”. En E.N. Chernyj (ed.): Kargaly II. Yazyki Slavianskoi kultury. Moskva: 170-174.

López-Sáez, J.A.; López García, P. y Martínez Navarrete, M. ${ }^{a}$ I. 2002: "Palinologicheskie issledovaniia na jolme Gornogo". En E.N. Chernyj (ed.): Kargaly II. Yazyki Slavianskoi kultury. Moskva: 153-165.
López Sáez, J.A.; Van Geel, B.; Farbos-Texier, S. y Diot, M.F. 1998: "Remarques paléoécologiques à propos de quelques palynomorphes non-polliniques provenant de sédiments quaternaires en France". Revue de Paléobiologie 17: 445-459.

López Sáez, J.A.; Van Geel, B. y Martín Sánchez, M. 2000: "Aplicación de los microfósiles no polínicos en Palinología Arqueológica”. En V.O. Jorge (ed.): Contributos das Ciências e das Technologias para a Arqueologia da Península Ibérica, Actas 3. ${ }^{\circ}$ Congresso de Arqueología Peninsular (Vila-Real, 1999) $I X: 11-20$. Oporto.

Mighall, T.M. y Chambers, F.M. 1993: "Early Mining and Metalworking: its impact on the Environment". The Journal of the Historical Metallurgy Society 27/2: 71-83.

Overpeck, J.T.; Webb III, T. y Prentice, I.C. 1985: "Quantitative Interpretation of Fossil Pollen Spectra: Dissimilarity Coefficients and the Method of Modern Analogs". Quaternary Research 23: 87-108.

Miller, N.F. 1984: "The Use of Dung as Fuel: an Ethnographic Example and an Archaeological Application". Paléorient 10, 2: 71-79.

Moore, P.D.; Webb, J.A. y Collinson, M.E. 1991. Pollen analysis. Blackwell. Oxford.

Montero Ruiz, I. 1994: El origen de la metalurgia en el sureste peninsular. Instituto de Estudios Almerienses. Almería.

Peterson, D. L. 2009: "Production and Social Complexity: Bronze Age Metalworking in the Middle Volga”. En B.K. Hanks y K.M. Linduff (eds.): Social complexity in prehistoric Eurasia: monuments, metals, and mobility. Cambridge University Press. Cambridge, New York: 187-214.

Popova, L.M. 2007: "A new historical legend: a long-term vegetation history of the Samara river valley". En L.M. Popova, Ch.W. Hartley y A.T. Smith (eds.): Social orders and social landscapes. Cambridge Scholars Publishing. Newcastle (Gran Bretaña): 95-119.

Presa, F. (ed.). 1997: Historia de las literaturas eslavas. Cátedra. Madrid.

Renfrew, C. 2009: "Foreword. From Myth to Method. Advances in the Archaeology of the Eurasian Steppe". En B.K. Hanks y K.M. Linduff (eds.): Social complexity in prehistoric Eurasia: monuments, metals, and mobility. Cambridge University Press. Cambridge, New York: xv-xx.

Riabinina, Z.N. 1998: Konspekt flory Orenburskoi oblasti. Uralskoe otdelenie Rossiskoi Academii Nauk. Ekaterinburg.

Rolland Calvo, J.; Martínez Navarrete, M. ${ }^{\mathrm{a}}$. y Vicent García, J.M. (en prensa 2010): "Economía política y minería prehistórica: el complejo minero-metalúrgico de Kargaly desde una perspectiva comparativa". En J. Sánchez-Palencia, A. Gilman y P. Bueno 
(eds.): Libro de homenaje a M. ${ }^{a}$ Dolores Fernández-Posse y de Arnáiz. Bibliotheca Praehistorica Hispana XXVIII, CSIC. Madrid: 163-182.

Rovira Llorens, S. 1999: "Una propuesta metodológica para el estudio de la metalurgia prehistórica: el caso de Gorny en la región de Kargaly (Orenburg, Rusia)". Trabajos de Prehistoria 56 (2): 85-113. http://tp.revistas.csic.es/index.php/tp/article/view/277/276 (acceso 19-11-2010).

Rovira, S. 2003: "Early copper metallurgy slags at Kargaly (Orenburg, Russia)". International Conference Archaeometallurgy in Europe (2003, Milan Italy) I: 479-486. Milano.

Rovira, S. 2004: "Tejnologiia vyplavki metalla i ego obrabotki". En E.N. Chernyj (ed.): Kargaly III. Yazyki Slavianskoi kultury. Moskva: 106-133.

Rovira, S. 2005: "Metallograficheski analiz mednogo tesla iz kurgana n. ${ }^{\circ} 1$ Pershinskogo nekropolia". En E.N. Chernyj (ed.): Kargaly IV. Yazyki Slavianskoi kultury. Moskva: 217-218.

Rovira, S. y Happ, J. 2004: "Eksperimentalnye raboty po vyplavke medi na Kargalaj arjaicheskim sposobom”. En E.N. Chernyj (ed.): Kargaly III. Yazyki Slavianskoi kultury. Moskva: 298-301.

Stockmarr, J. 1971: "Tablets with spores used in absolute pollen analysis". Pollen et Spores 13: 615-621.

Stöllner, Th. 2003: "Mining and Economy. A Discussion of Spatial Organisations and structures of Early Raw Material Exploitation". En Th. Stöllner, G. Körlin, G. Steffens y J. Cierny (eds.): Man and Mining. Studies in honour of Gerd Weisgerber. Der Anschnitt 16: 415-446. Bochum.

Tarasov, P.; Williams, J.W.; Andreev, A.; Nakagawa, T.; Bezrukova, E.; Herzschuh, U.; Igarashi, Y.; Mü- ller, S.; Werner, K. y Zheng, Z. 2007: "Satelliteand pollen-based quantitative woody cover reconstructions for northern Asia: Verification and application to late-Quaternary pollen data". Earth and Planetary Science Letters 264, 1-2: 284-298.

Thornton, Ch. P. 2009: "Archaeometallurgy: Evidence of a Paradigm Shift?". En T.L. Kienlin y B.W. Roberts (eds.). Metals and Societies. Studies in honour of Barbara S. Ottaway. Universitätsforschungen zur Prähistorischen Archäologie 169. Aus dem Institut für Archäologische Wissenschaften der Universität Bochum Fach Ur- und Frühgeschichte. Dr. Rudolph Habelt GmbH. Bonn: 25-33.

Uzquiano, P. 2002: "Prilozhenie 1. Opredelenie drevesnyx ostatkov s Gornogo". En E.N. Chernyj (ed.): Kargaly II.Yazyki Slavianskoi kultury. Moskva: 166-169.

Vicent García, J.M.; Ormeño, S.; Martínez Navarrete,

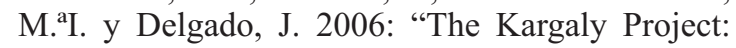
modelling Bronze Age landscapes in the steppe". En S. Campana y M. Forte: From Space to Place: $2^{\text {nd }}$ International Conference on Remote Sensing in Archaeology. Proceedings of the $2^{\text {nd }}$ Internationl Workshop, CNR, Rome, Italy, December 4-7, 2006. British Archaeological Reports S1568, Archaeopress. Oxford: 279-284.

Vicent García, J.M.; Rodríguez Alcalde, A.L.; López Sáez, J.A.; Zavala Morencos, I. de; López García, P. y Martínez Navarrete, M. ${ }^{\text {II. }}$ 2000: “¿Catástrofes ecológicas en la estepa? Arqueología del Paisaje en el complejo minero-metalúrgico de Kargaly (Región de Orenburg, Rusia)". Trabajos de Prehistoria 57(1): 29-74. http://tp.revistas.csic.es/index.php/tp/ article/view/260/260 (acceso 19-11-2010). 